\title{
منهجية مقترحة لتصميم وتنفيذ المساجد من خلال تطبيق معايير تكنولوجيا البناء المعاصرة
}

\section{A proposed methodology for designing and building mosque by applying modern building technology criteria}

\author{
م/ سارة عبد الهادى على سيد ـأ.م.د/ نسرين فتحى عبد السلام
}

المسجد هو مركز دينى وثقافى واجتماعى، و إذا كانت الوظيفة الأساسية للمسجد هو أنه مكان للصلاة فهو أيضا مكان للدرس وملتقى للتو اصل بين المسلمين وتمت به العديد من المهام منذ النشأة الأولي للدولة الإسلامية، وقد

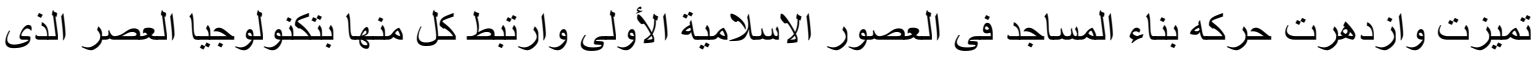

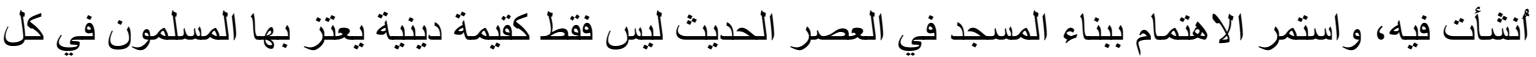

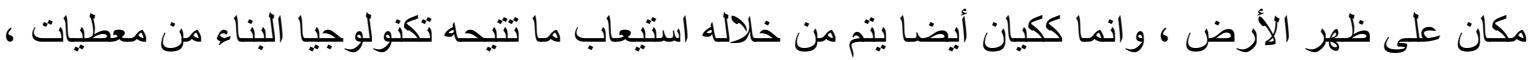

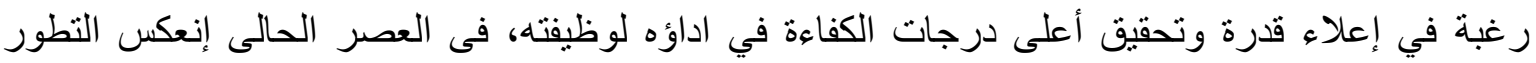
التكنولوجى على بناء المساجد محليا وعالميا ، وظهر إستخدام افكار مبتكرة و ومواد وطرق انشائية جديده

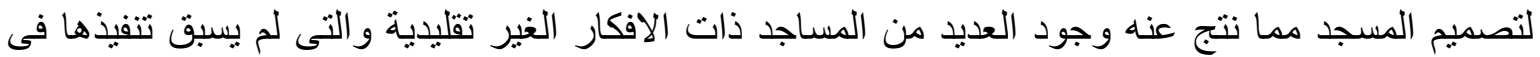

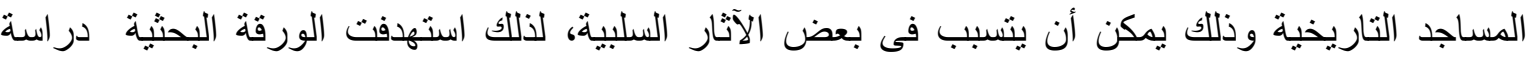

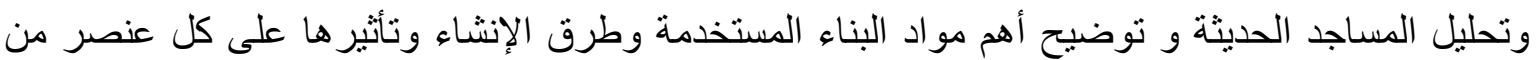

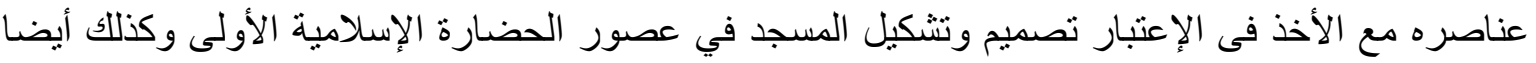

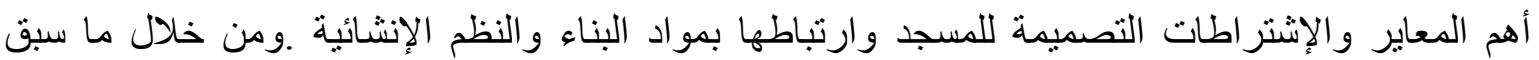

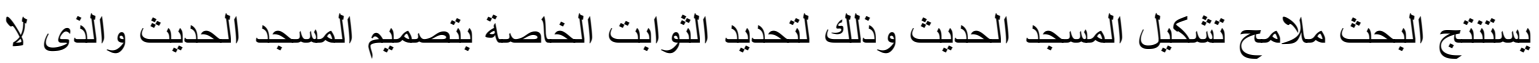

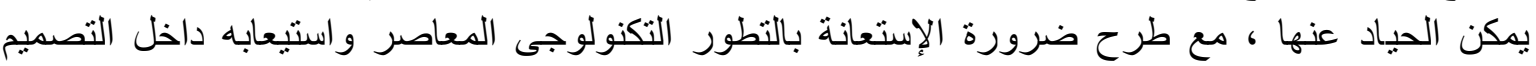
الحديث للمسجد.

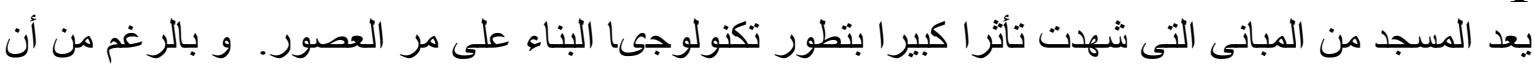

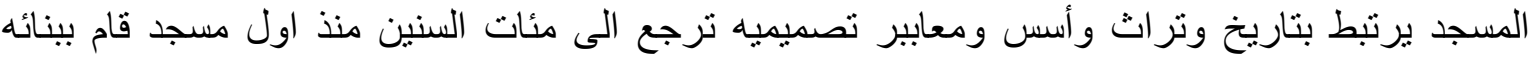

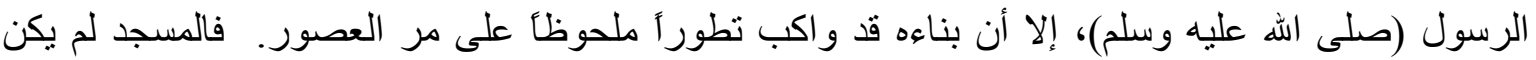

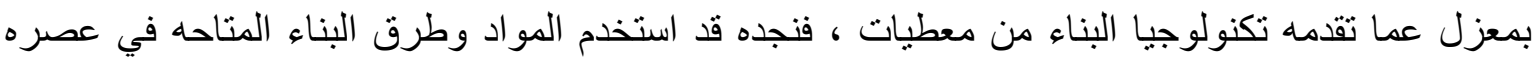
وبيئته، ليظهر فى ازهى صوره له . وكلما تو افرت تقنيات ومعطيات تكنولوجية جديدة نجده يتأثر بها ويضمها

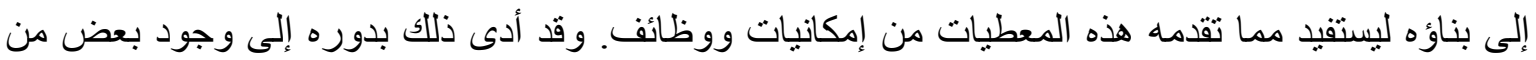

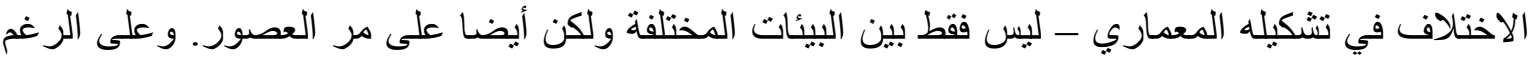

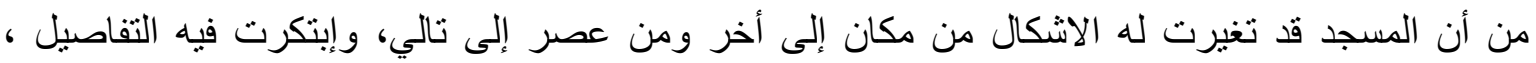

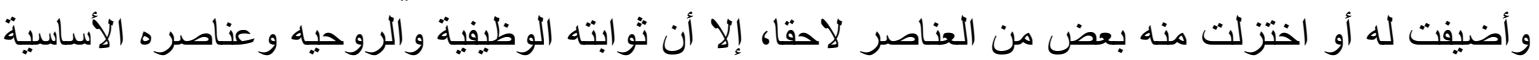

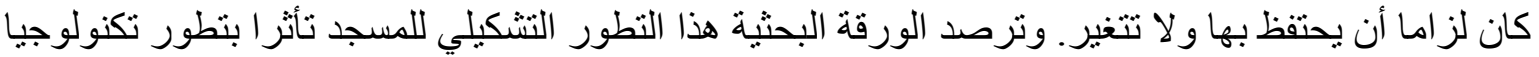
البناء ومعطياته المتتابعة ، تأسيسا على التشكيل التقليدي الذي تركته الصورة التئه الذهنية للمساجد في العصور 


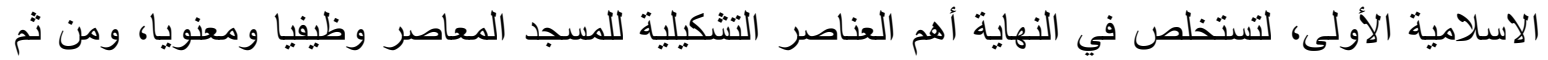
محددات تطبيق التقنيات المعاصرة التي تؤثر تأثثر ا مباشر ا في هذا التشكيل.

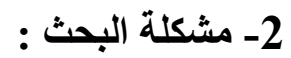

أدى التطور التكنولوجى لمواد ونظم وطرق البناء إلى ظهور اشكال و افكار جديده لتصميم المساجد في التهي

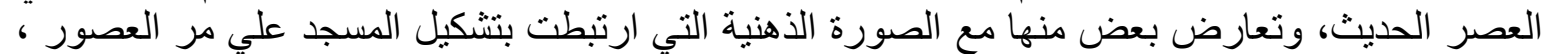

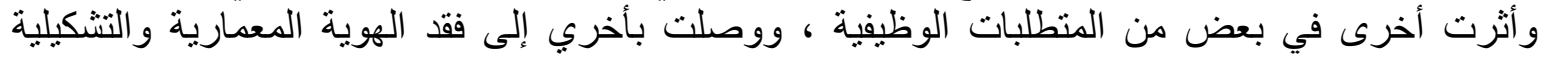

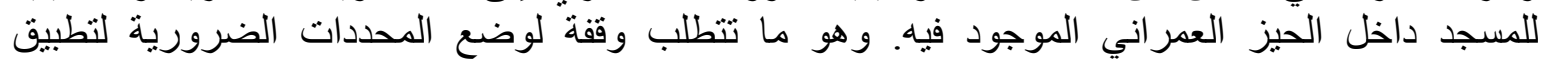
المعطيات التكنولوجية الحديثة عند تصميم وتشكيل المسجد في في العصر فئ الحديث.

$$
\text { 3- بتمثل الهداف البحث الرئيسي للبحث في: }
$$

ـ الوصول إلى منهجية لتصميم وتنفيذ المساجد من خلال تطبيق معايير تكنولوجيا البناء المعاصرة وفي سبيل تحقيق هدفه الرئيسي يستهدف البحث أيضا:

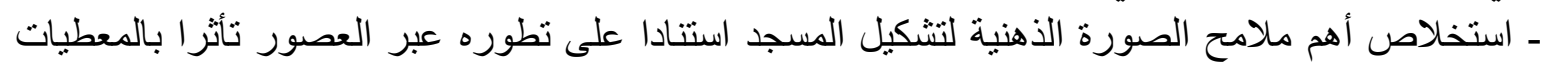

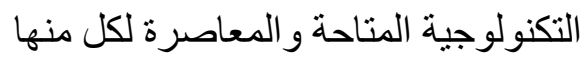
ـ تحديد الاثار السلبيه لتأثير التطور التكنولوجى على عماهولى عاره المساجد المعاصره وكيف يمكن تفاديها فى تصميم ونتكيل عناصر المسجد الحديث وتحويلها إلي إيجابية .

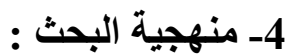

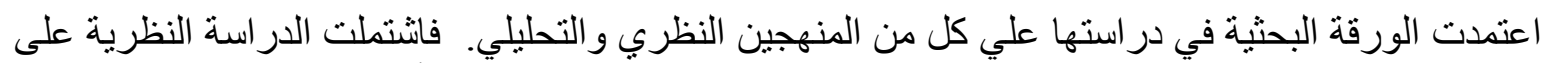

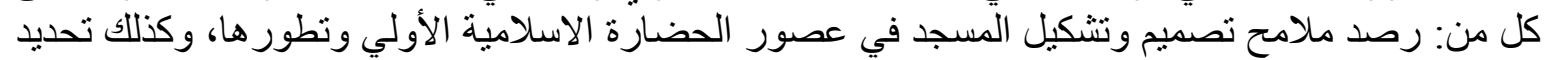

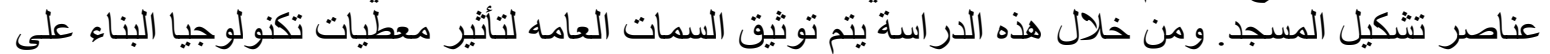
المسجد، واستخلاص المحددات التصميميه للمساجد ومتطلبات توظيف معطيات تكنولوجيا البناء، والتي التي التياء

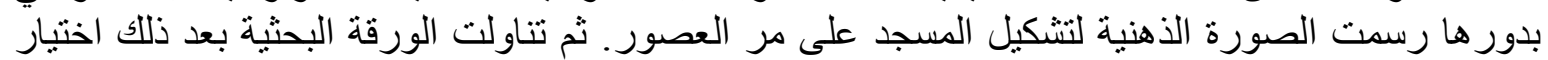

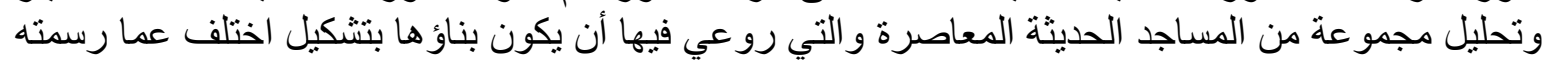

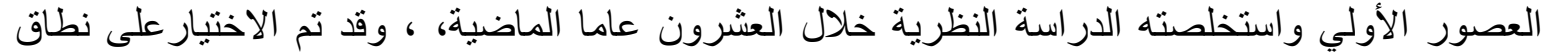

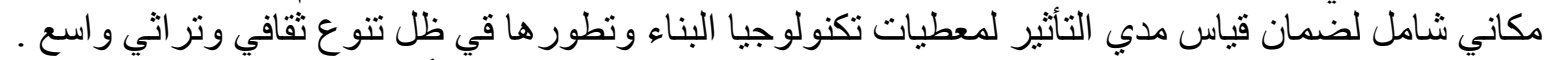

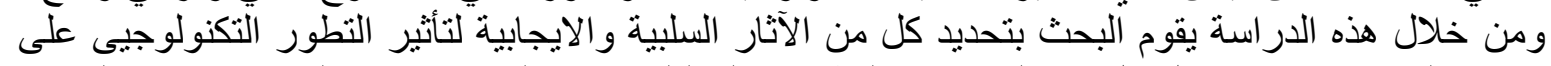

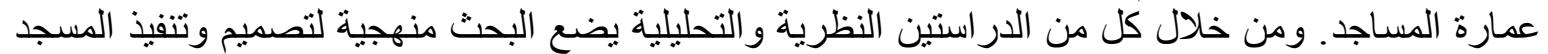

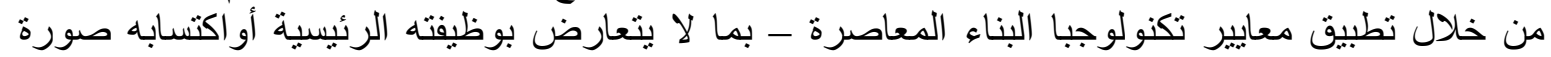

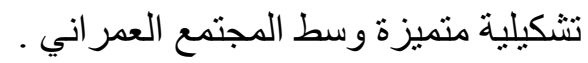

\section{5- تصميم وتثكيل المسجد في عصور الحضارة الإسلامية الأولى الميل}

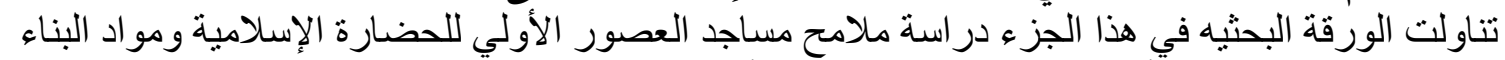

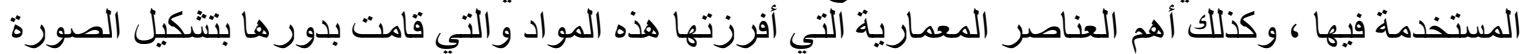

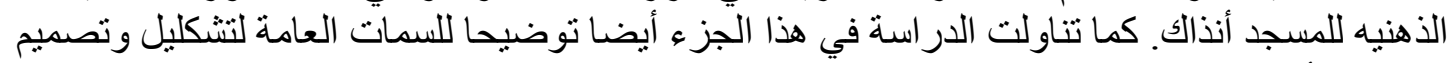
المساجد بأنو اعها المختلفة.

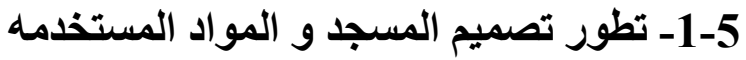

كونه كونه فناء مستطيل محاط بأربعة جدر ان من اللبن ومكان للصلاة سقفه من الجريد و أعمدته من جذوع الرئه النخل. 
وقد خلا المسجد من الزخارف. و لم يكن بالمسجد النبوي الأول محر ابا أو منارة (مئذنة) في عهد الرسول

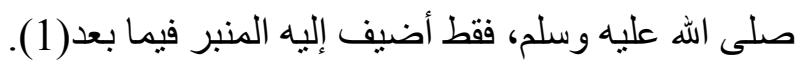

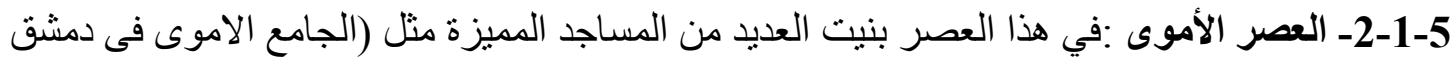

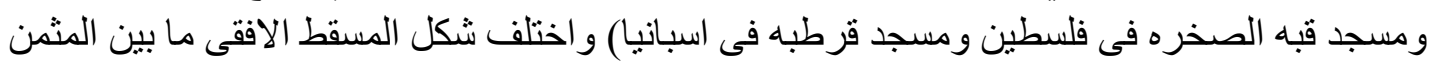

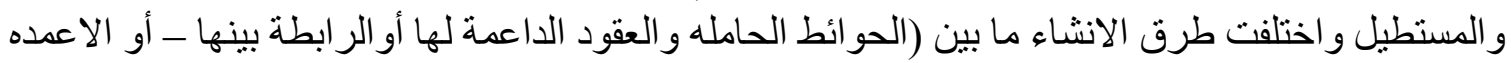

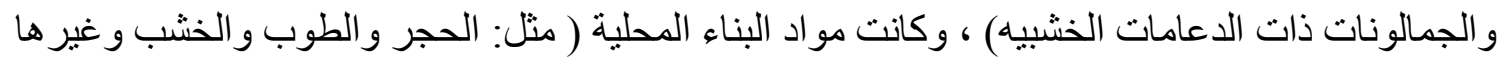

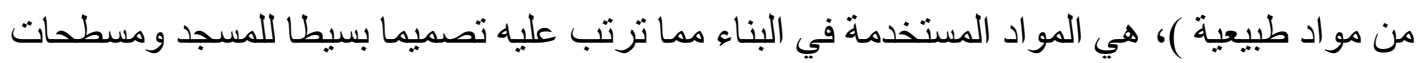
محدودة(2). من موردي

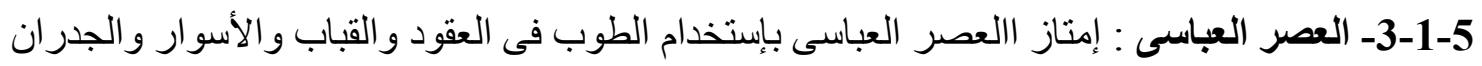

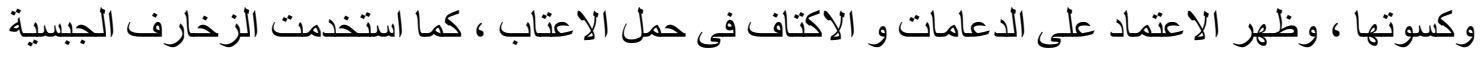

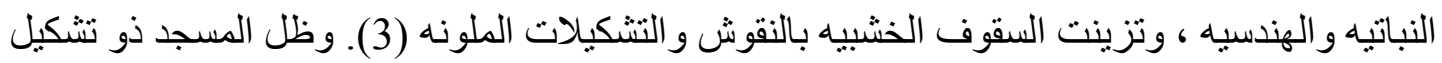

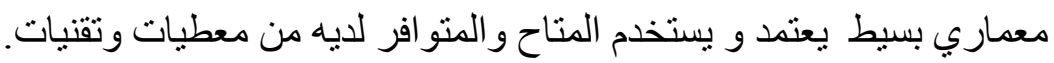

(j-4-1-5 العصر الفاطمى : فى العصر الفاطمى تم الاعتماد على الطوب كماده أساسيه للبناء وأدي ذلك إلى كلى

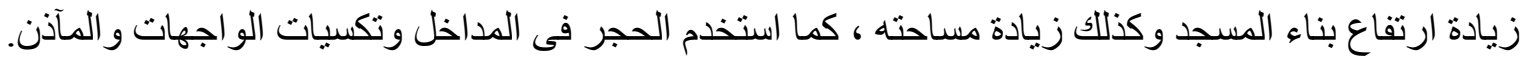

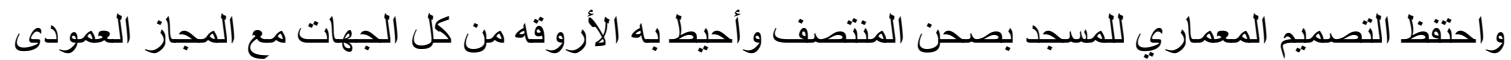

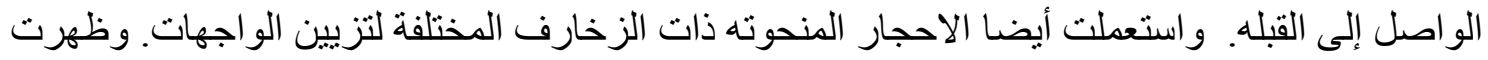
أيضا فكرة دمج و إضافة المحال التجارية أسفل واجهات المساجد كما في مسجد الصالح طلائع (4).

5-1-5 - العصر الأيوبى : ظهر المسجد المدرسه من أجل تدريس المذاهب الاربعه ، وكان المسقط الافقى

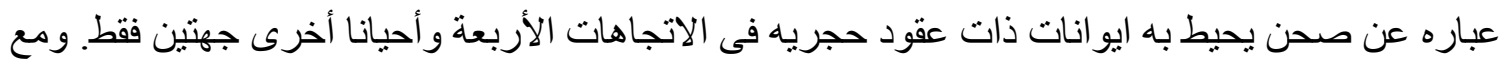

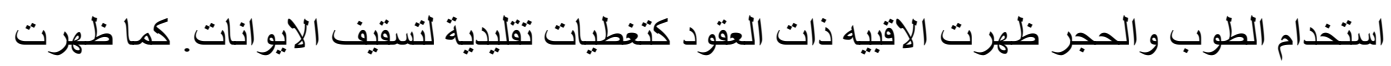
المقرنصات أيضا لنقل الأحمال من القباب إلى العقود و الحو ائط ، لتجمع بين وظيفتها كعنصر إنهات إنشائي

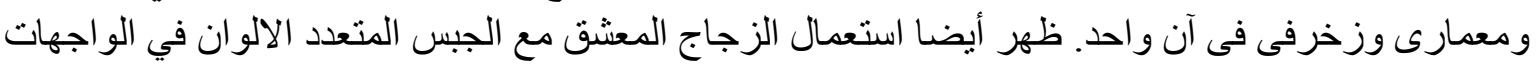
بالإضافة إلى الرخام في أعمال التكسيات (5).

6-6-1-5- العصر المملوكى : تميز العصر المملوكي بالمبانى الدينيه التي خصصت لايو اء المنقطعين للعباده ،

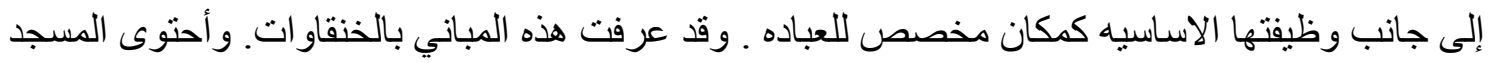

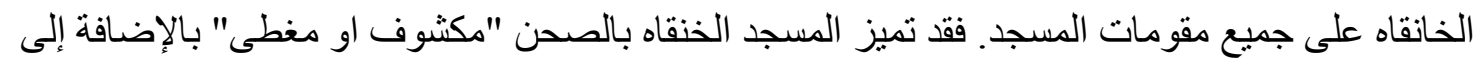

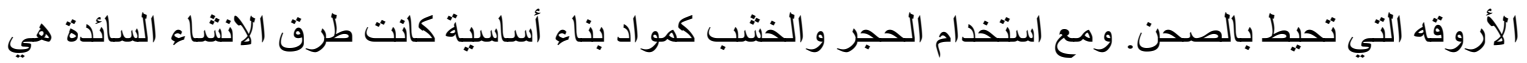

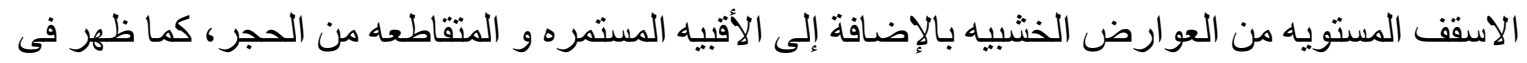

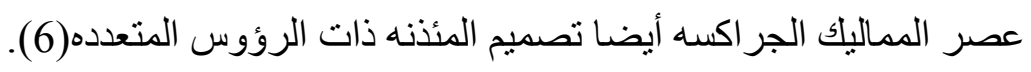




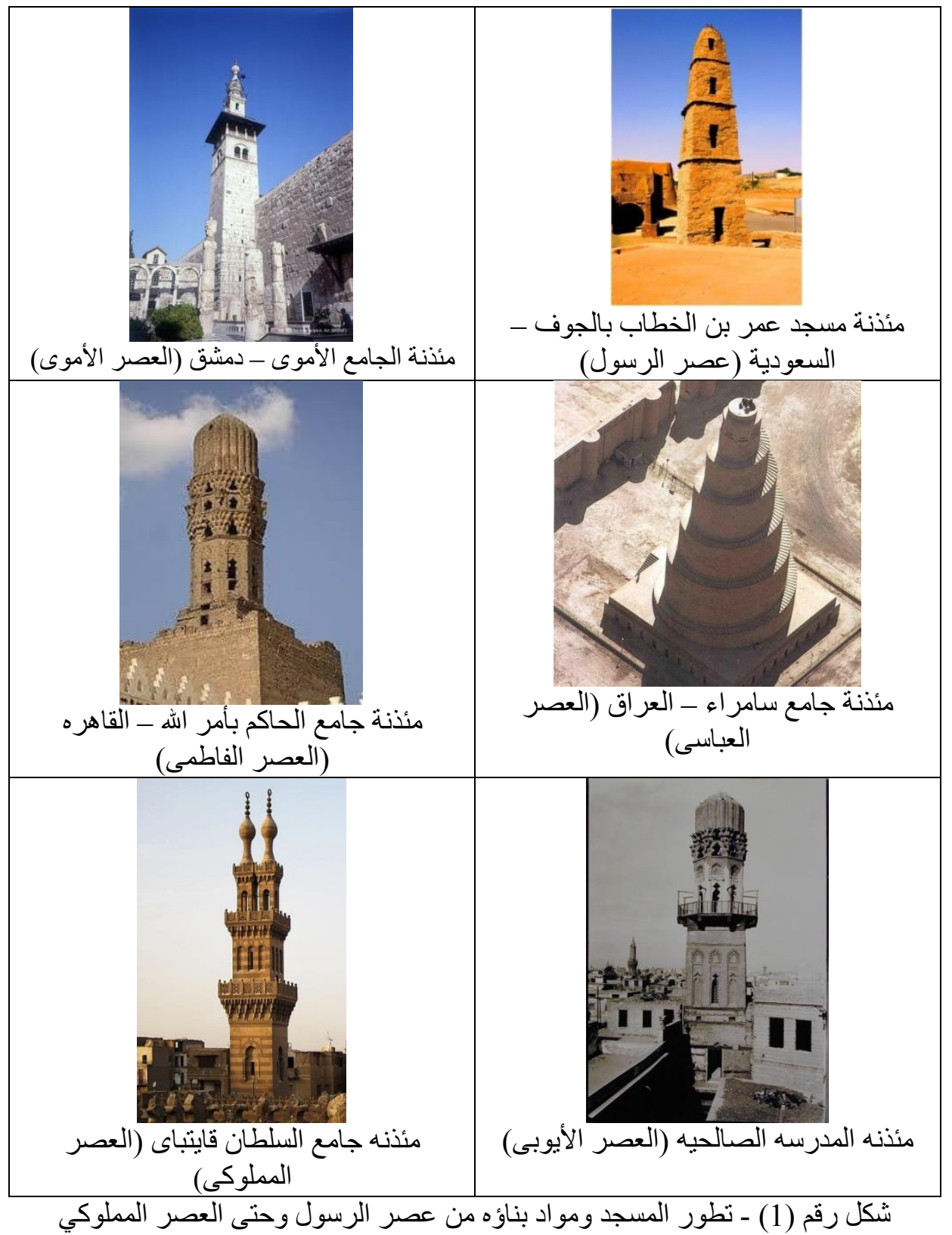

-7-1-5 العصر العثمانى : تطورت المساجد فى هذا العصر من حيث التصميم فساحة الصلاة الأساسية تبنى

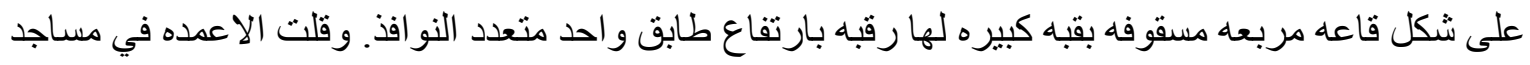

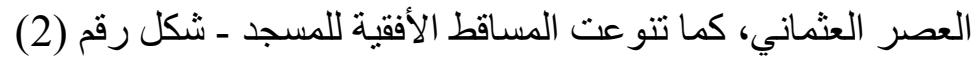

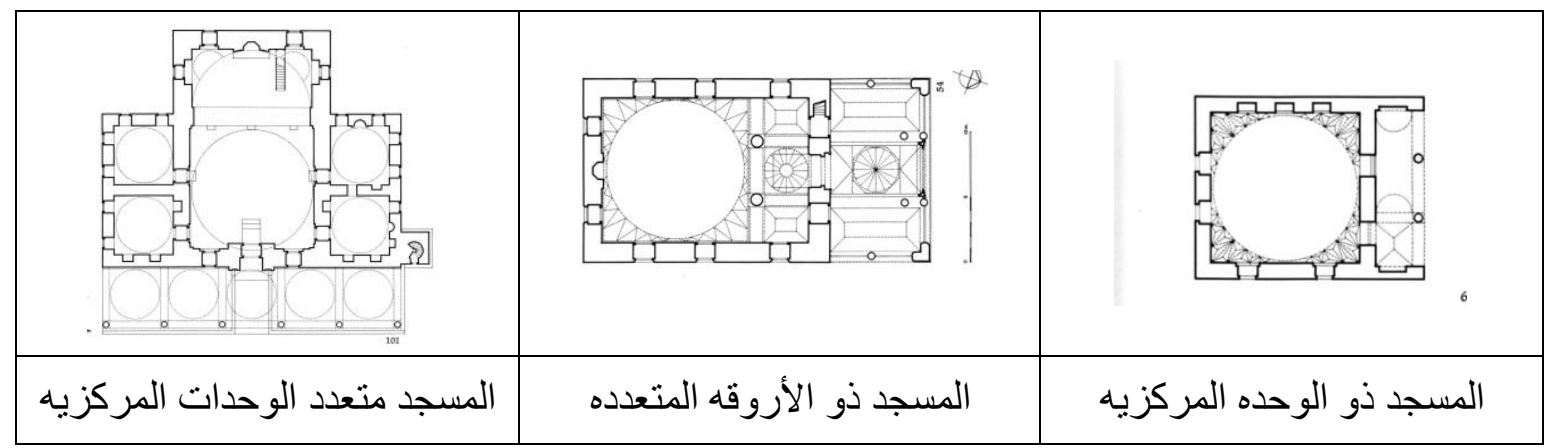




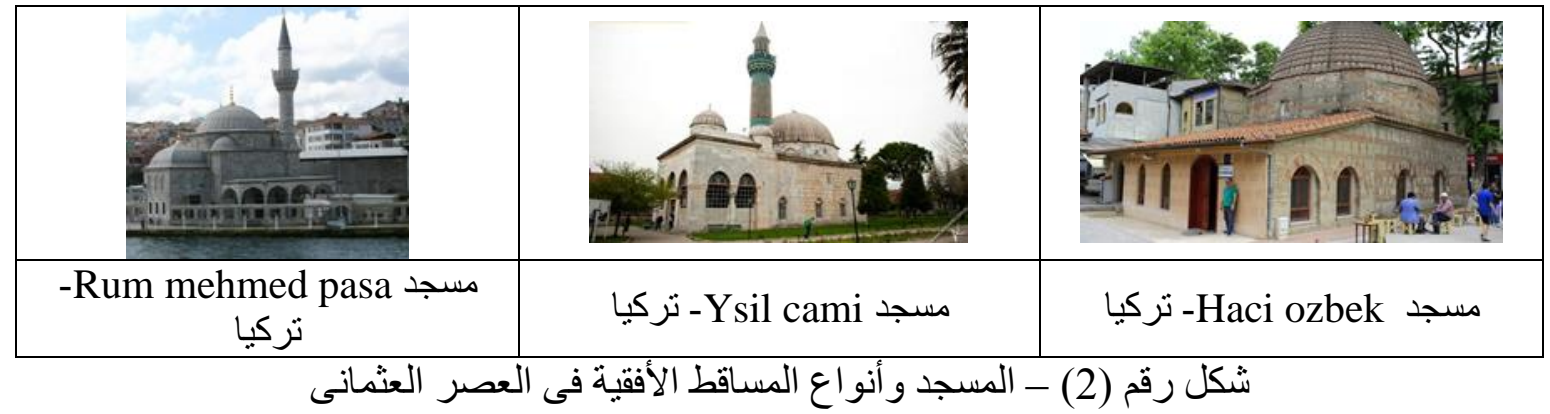

ومع الاعتماد على الحجر كمادة أساسية في البناء حلت القباب و القبو ات محل الأسقف الجمالونية الخشبية،

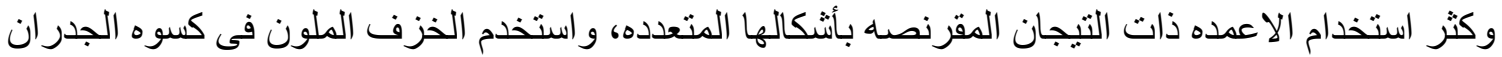

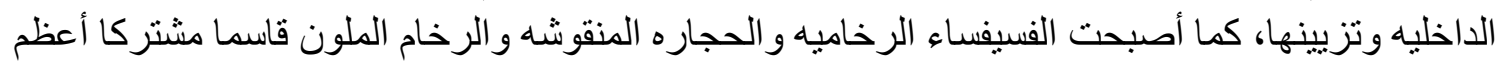

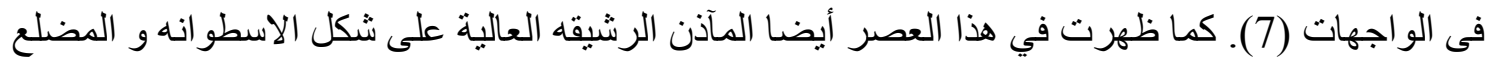
الكثير الاضلاع وسقفت بنهايات مخروطيه الثكل مصفحه بالرصاص. فـاص.

\section{-2-5 عناصر تثكيل مسجد العصور الإسلامية الأولي}

كانت عناصر تشكيل وبناء المسجد في عصر الحضارة الاسلامية الأولى انعكاسا مباشرة لمو اد البناء. وتغيرت

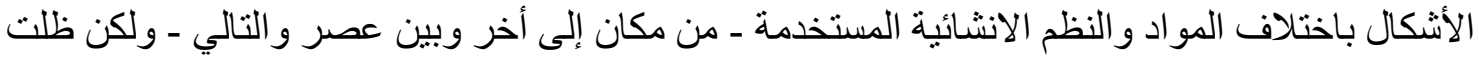
العناصر التي تشكل المسجد واحدة. وتوجز هذه العناصر فيما يلي:-

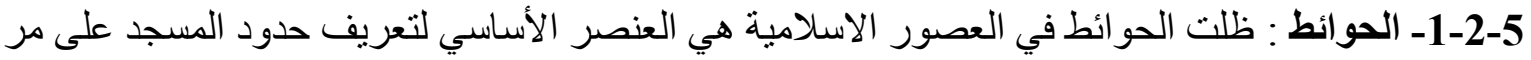

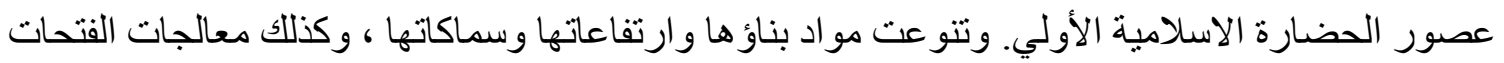

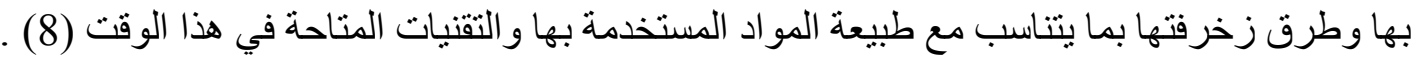
وات

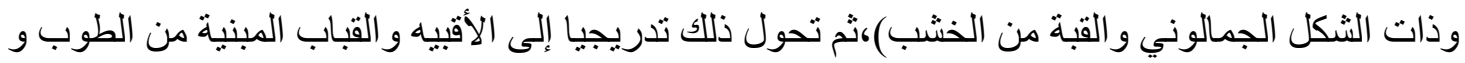

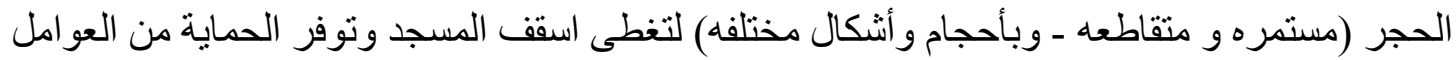

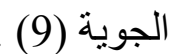

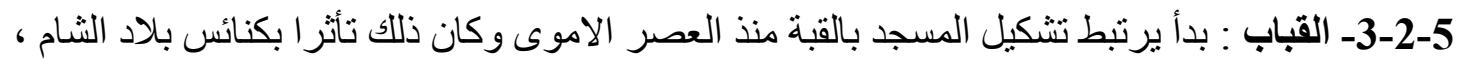

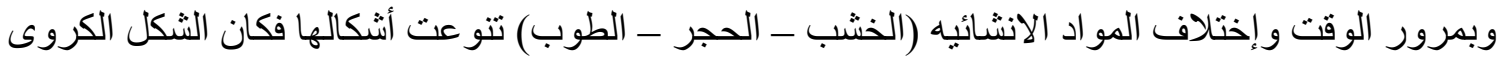

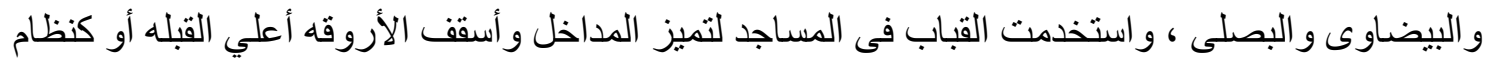
إنثائى رئيسى (كقبه مركزيه تغطى قاعه الصلاه)، كما استخدمت ايضا لتغطيه الاضرحه الملحقه

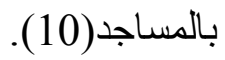

4-2-5 العقود : تعتبر العقود هي العنصر الانشائي المكمل لاستخدام القباب و القبوات في البناء. وقد

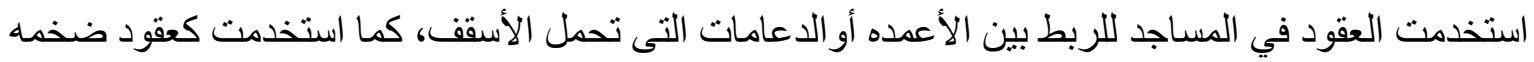

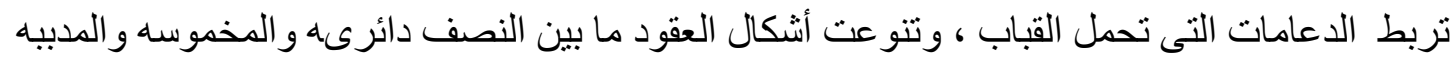

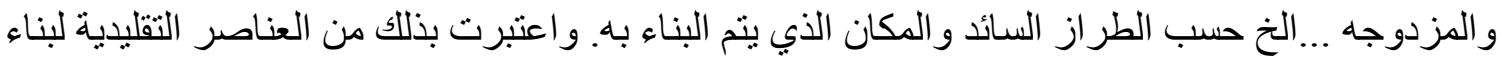

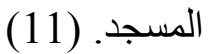

5-5-5 الأعمده : استخدمت الأعمدة منذ عصر الرسول (صلى الله عليه وسلم) في بناء المسجد النبوي.

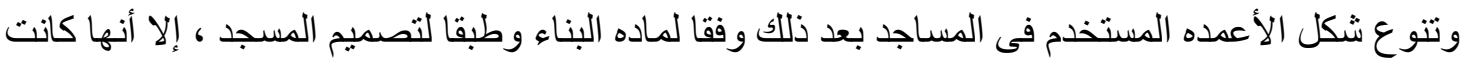

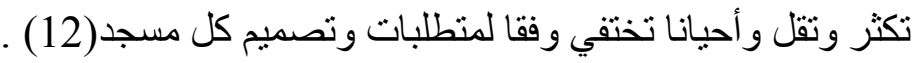




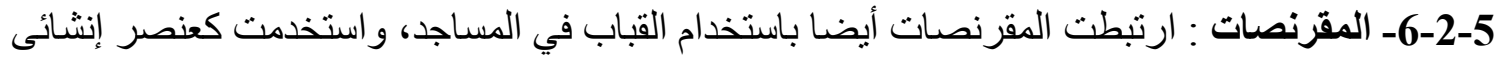

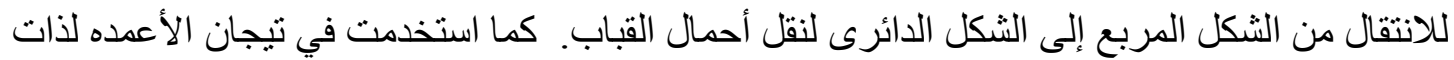

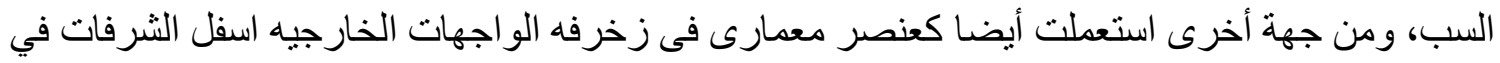

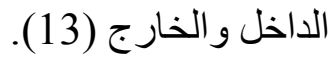

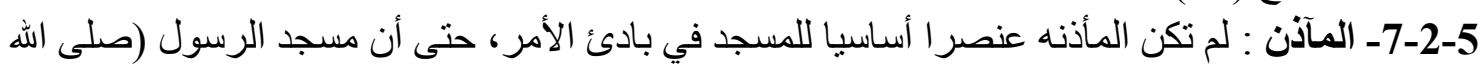

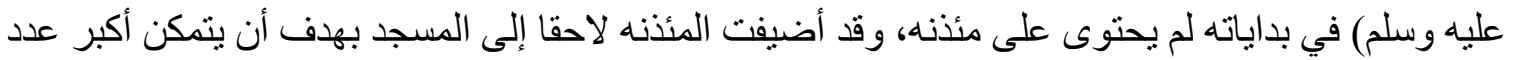

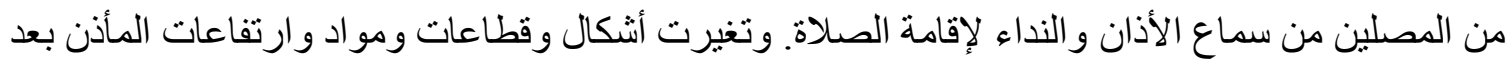

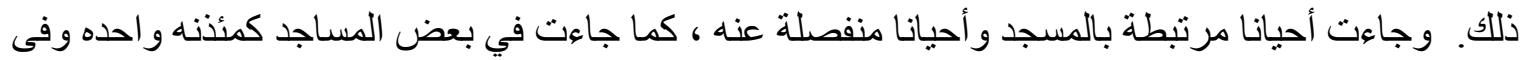

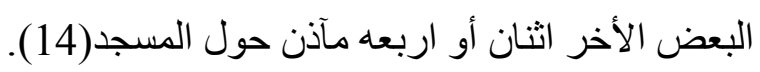

-8-2-5 المحراب والقبله : يعتبر المحر اب "الحنيه أو التجويف الموجود فى جدار القبله" من العناصر

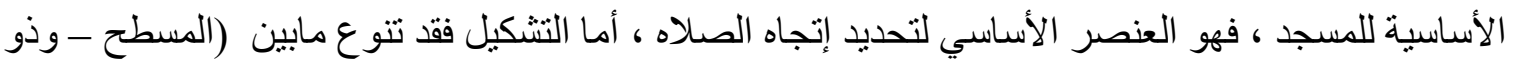

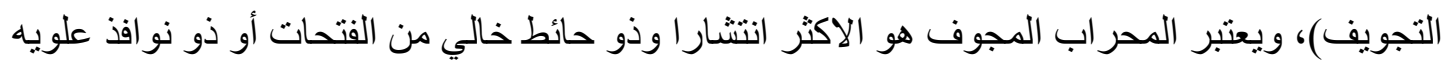
مرتفعه علي أقصي تقدير (15). وك ان أو المنبر : هو المكان الذى يرتقى إليه الإمام لإلقاء الخطبه فيكون مرئيا ومسمو عا لدى جميع الدصلين،

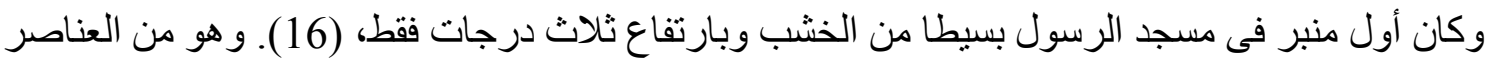
المكملة لاستيفاء الوظيفة الأساسية للمسجد.

وهات الثكرفات : هى وحدات هندسيه متكرره تحيط بأعلى سقف المسجد للأغر اض المعمارية والجمالية،

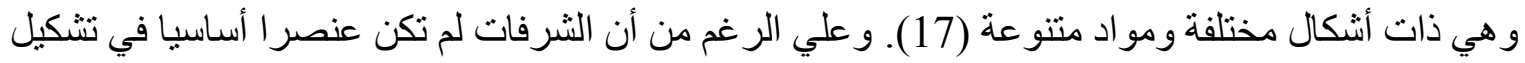

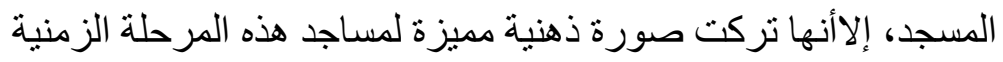

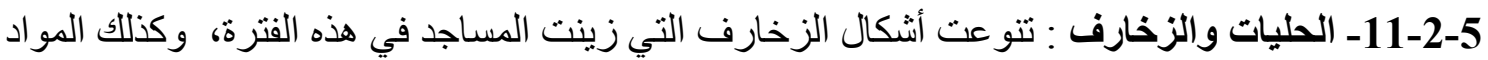

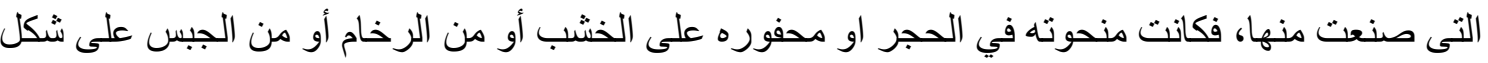

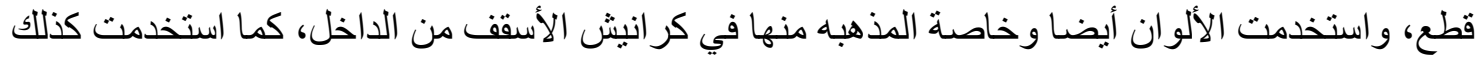

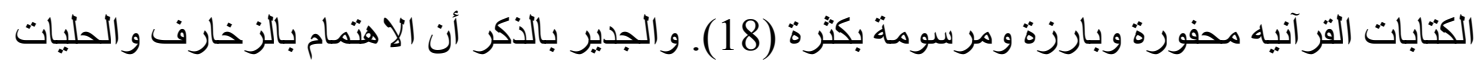

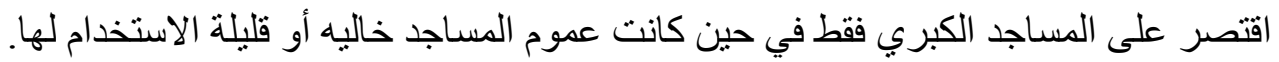

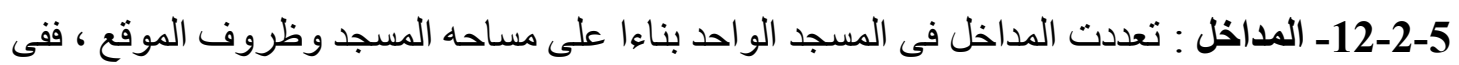

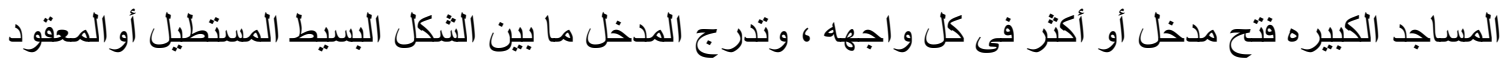

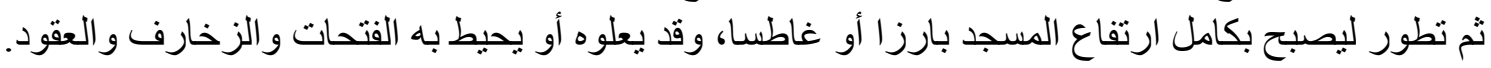

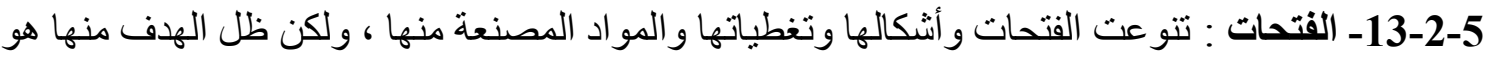
الإضاءة والتهوية وتحقيق الخصوصية وتوفير الهدوء للمصلين بعيدا عن الانثغال بما يحدث في الخارج أنثاء

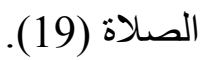

\section{3-5 السمات العامه لتأثير معطيات تكنولوجيا البناء على المسجد (في العصور الاسلامية الأولى)}

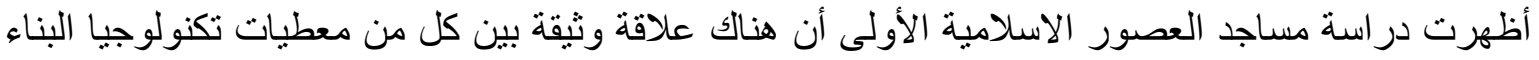

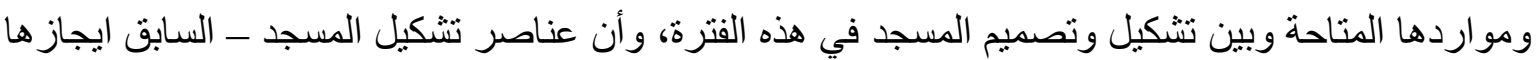

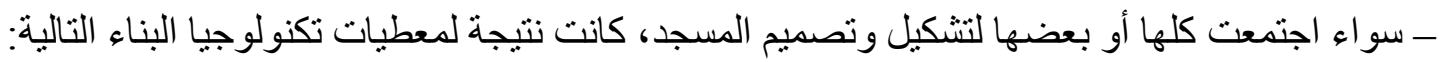


- - مو اد البناء المحلية الطبيعية المتو افرة في البيئة المكانية للمسجد.

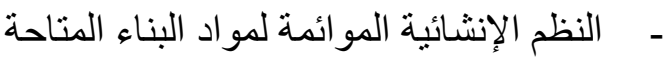

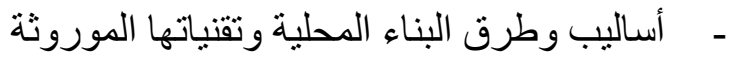

وقد أدى ذلك بدوره إلى أنه بالرغم من وجود مجمو عة من الملامح العامة التى شكلت الصورة الذهنية التهنية التقليدية

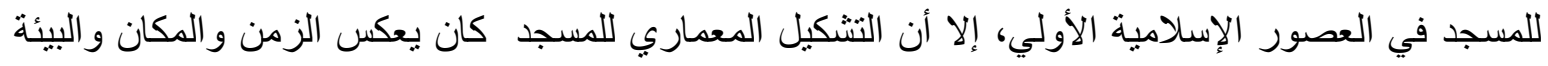
الأذين أنشـئ فيهم. الجدير بالذكر أيضا أن عناصر تشكيل المسجد الوظيفية - يمكن تجريدها في العناصر التي تحقق الخصوصية

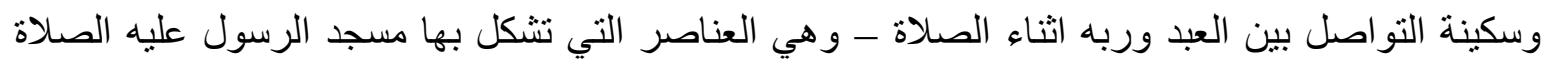

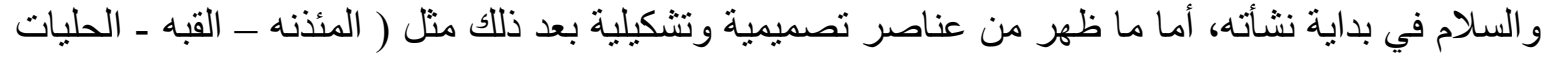

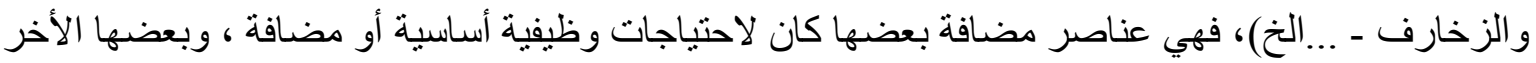

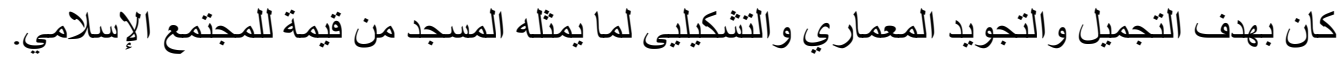

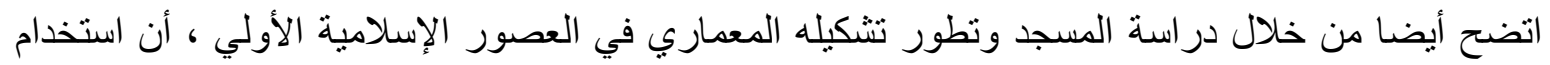

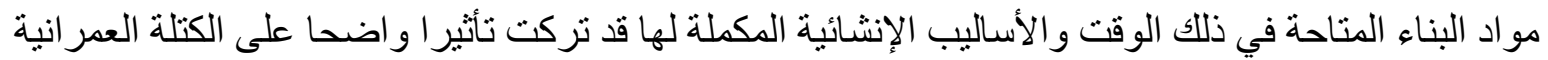
الثقيلة لفراغات المسجد أفقيا ورأسيا. وقد ظهر ذللك في صغر المساحات نسبيا وكثرة العناصر الإنشائية

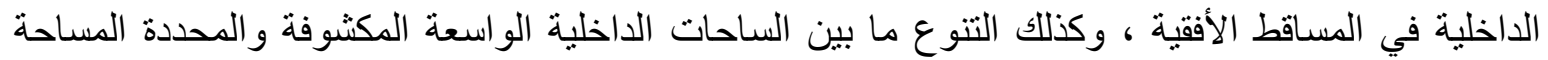

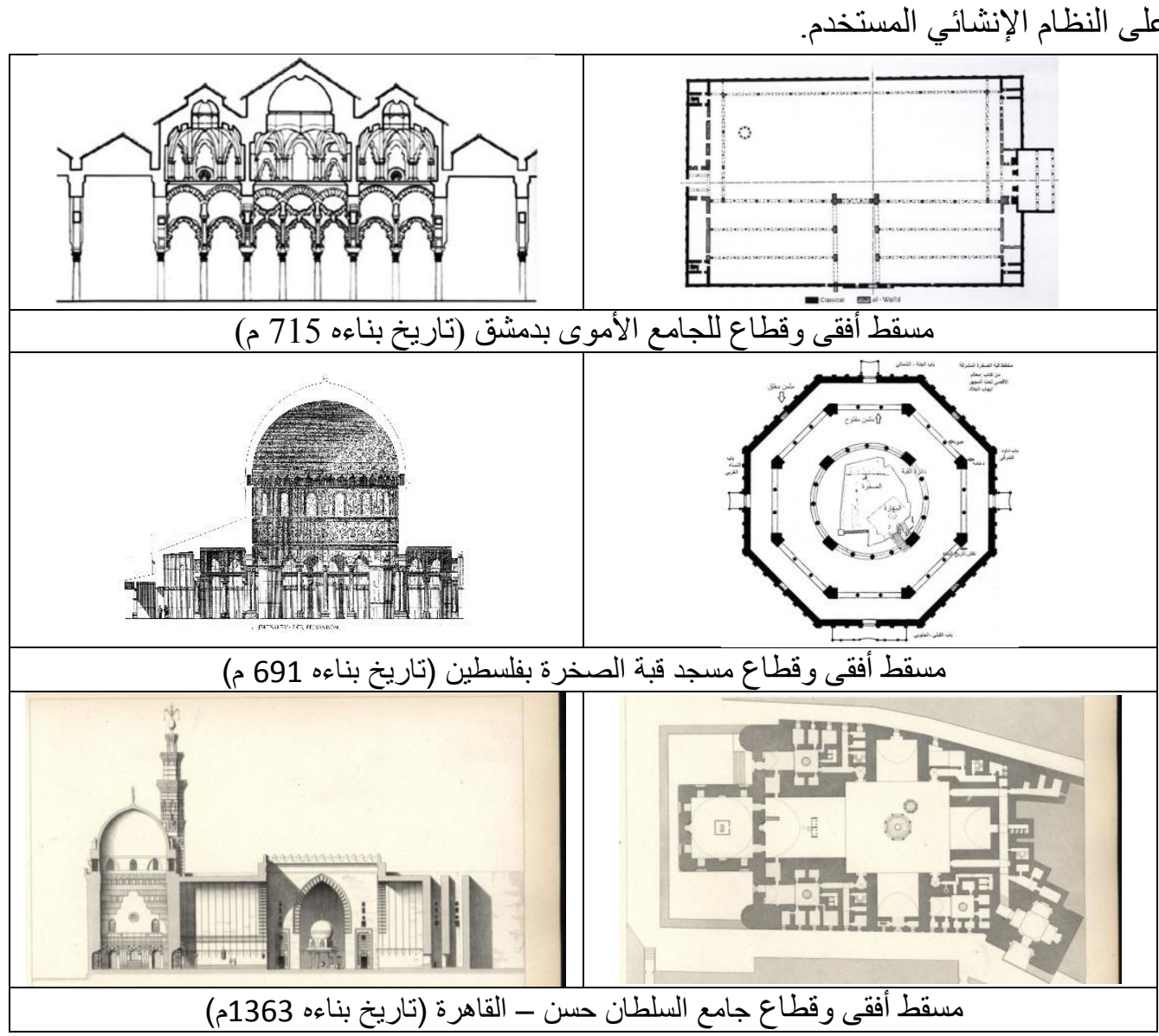




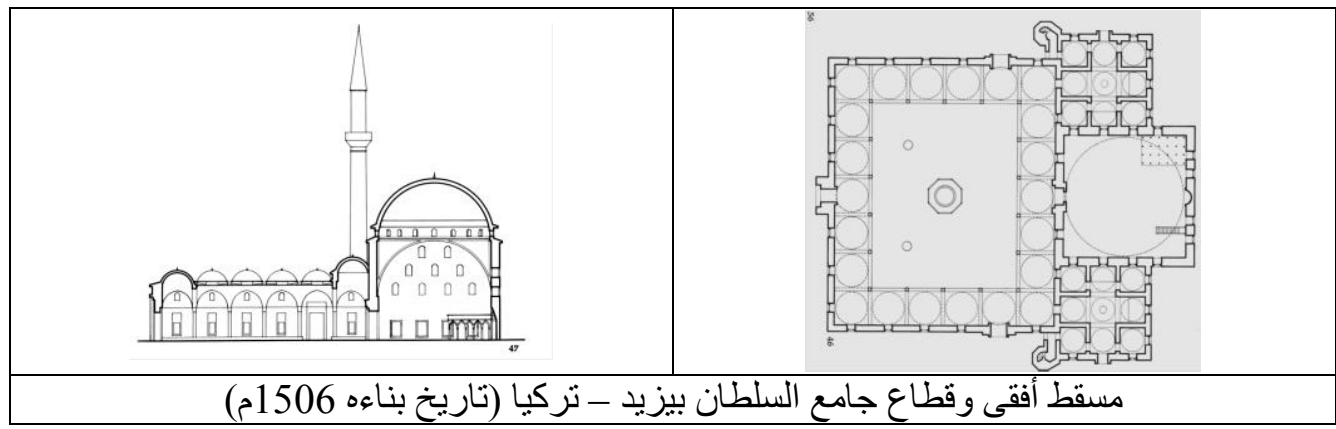

شكل رقم (3)- تأثير مو اد ونظم البناء في العصور الأسلامية الأولى على المساقط الأفقية للمسجد وتغطياته

\section{6- المحددات التصميميه للمساجد ومتطلبات توظيف معطيات تكنولوجيا البناء}

أظهرت در اسة مساجد العصور الإسلامية الأولي، مجموعة من الاعتبار ات التصميمية التي أثرت أيضا على التى الته

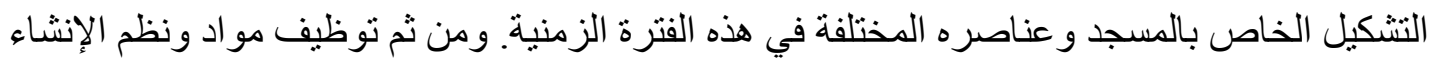

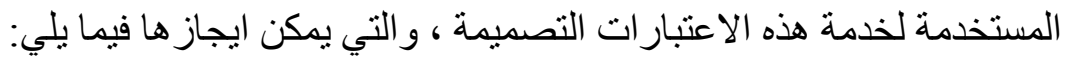
1-6 قاعة الصلاة: ـ مكان وقوف المصلين بتجاه القبلة ، ويفضل الأشكال التى تجعل الصف الأول اكبر الصفوف (مستطيل -

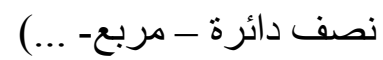

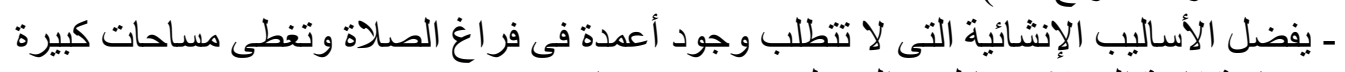
ـ ـ مساحة قاعة الصلاة تبعا لعدد المصلين وتقدر تقريبا 1م2 (20)

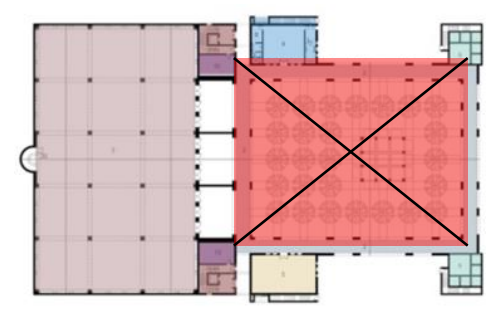

شكل رقم (4) - الصحن الككشوف الخارجى

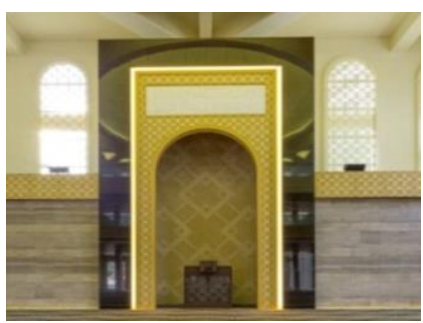

شكل رقم (5) - حائط القبلة وهى بارزة للخارج

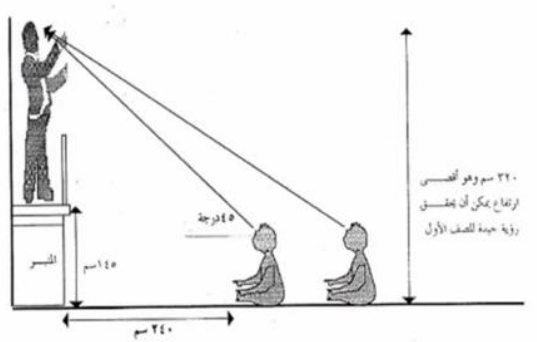

شكل رقم (6) - قطاع يوضح المنبر
2-6 الصحن المكثوف:

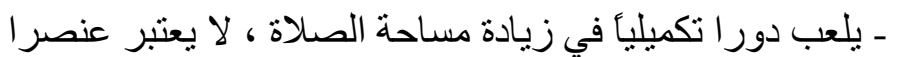

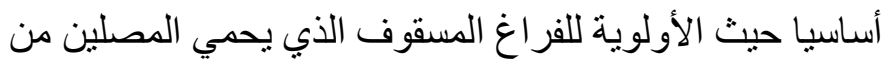

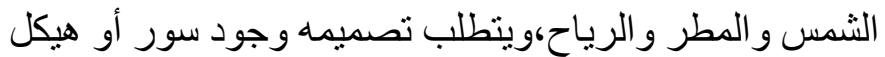
خارجى مرتفع يحيط باه ويحدد مساحته. - وجود الصحن يتوقف على الظروف المناخية للمنطقة و مساحة الأرض ونوع المسجد (21).

3-6 حائط القبلة

حائط تحديد قبلة الصلاة ويوضلة

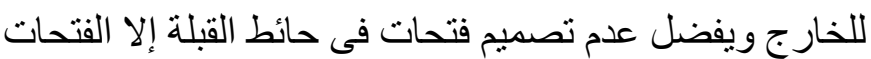

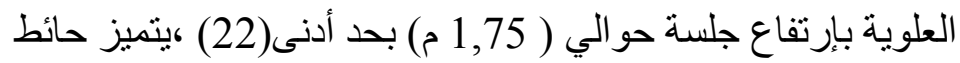
القبلة بمو اد تشطيب مختلفة عن بارتى حو ائط المسجد.

4-6 الوظيفة الأساسية للمنبر تكون في توجيه الصوت وتوفير الرؤية

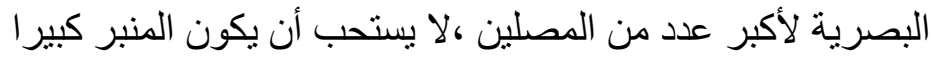

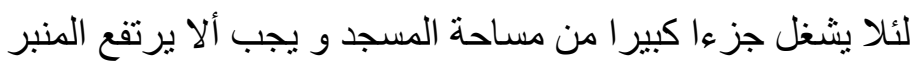

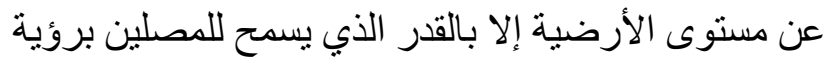

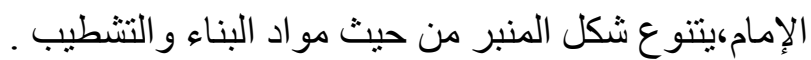




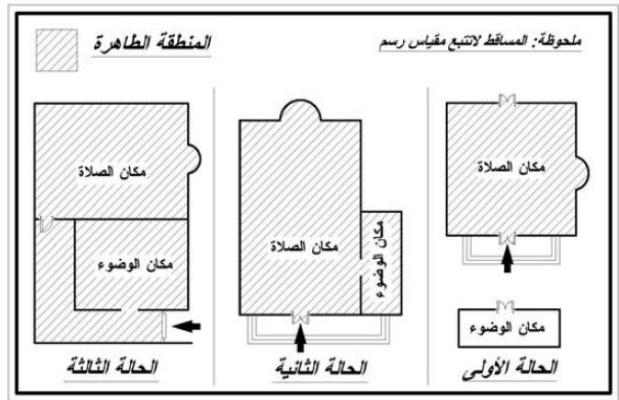

$$
\text { أـ دور ات خدمات المسجد المياه و الوضوء }
$$

يمكن اقامتها فى المسجد شرط أهر أن تكون فى مكان بعيد عن مكان الصلاه أو الفصل بينهم بممرات أفي الفئ

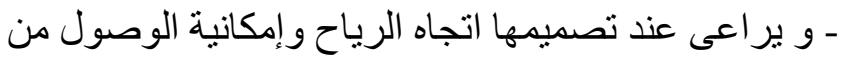

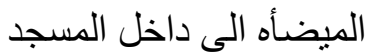

شكل ر قم (7) علاقة هنطقة الو ضو ء بمكان الصلاة

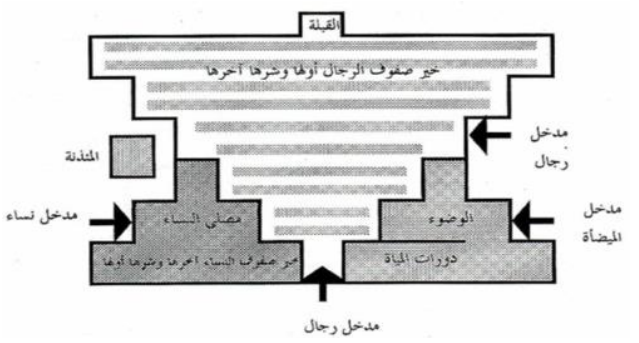

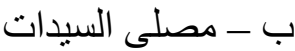
- يجب أن يستقل مصلي النساء بمدخل خاص بعيدة عن مداخل الرجال

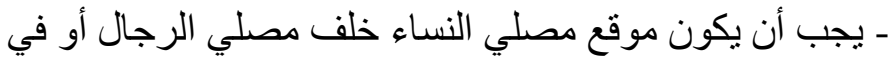
دور علوي ومن الخلف أيضا ، على أن يكون معزو لا بساتر

يحجب الرؤية(23). شكل رقم (8) - موقع مصلى السيدات فى إن تخطيط السند ملثد

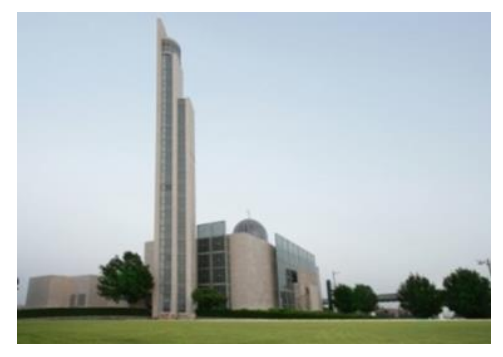

شكل رقم (9) - ارتفاع المئنة بالنسبة

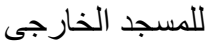

$\underline{\text { 6-6 }}$ - يجب حساب ارتفاعها المناسب بالنسبة للبيئة الخارجية لتكون

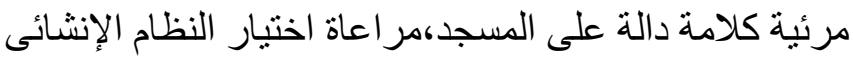

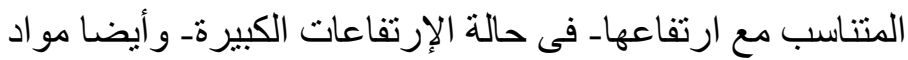
التشطيب المميزة المستخدمة على الهيكل الخارجى.

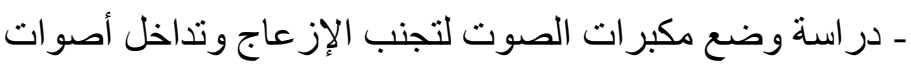
الأذان مع المساجد المحيطة ميرة

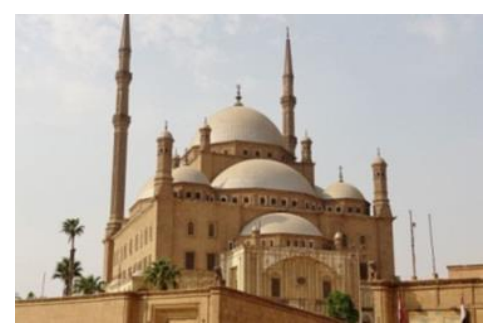

7-6

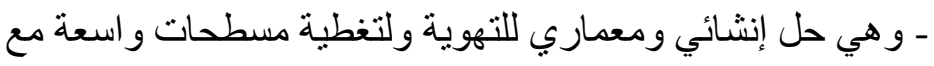
تفادي كثافة الأعمدة الحاملة و التى تقع وسط قاعة الصعلاة - وليس للقبة شكل محدد وهى غير مرتبطة وظيفيا بعناصر شكل رقم (10) - قباب جامع محمد على

8-6 الفتحات

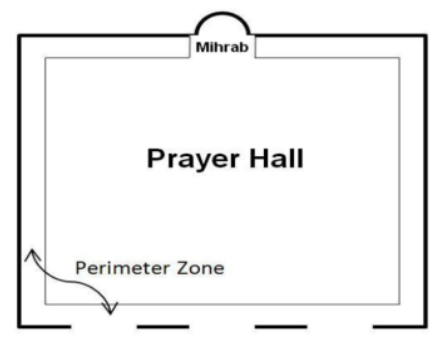

شكل رقم (11) - مسقط افقى يوضح أملكن فتحات الأبواب (11 من

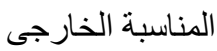

- مر اعاة ارتفاع النو افذ فى حائط القبلة ، وتتأثر مساحة الفتحات

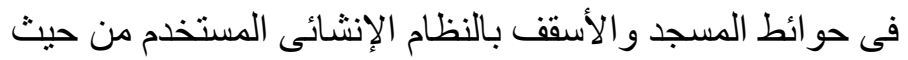

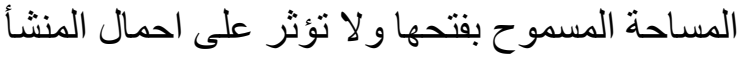

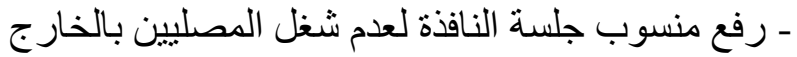
ـ حساب مساحة الفتحات لتوفير التهوية المناسبة ـ تصميم المداخل فى الحائط الخلفى للمسجد و الحو ائط الجانبية ،

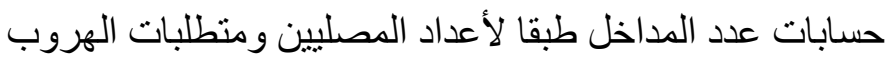

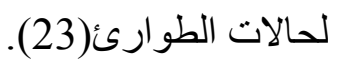




\section{7- تثنكيل المسجد في العصور الأسلامية الحديثة}

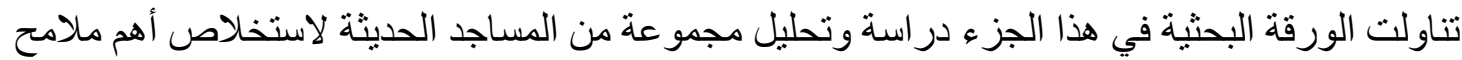

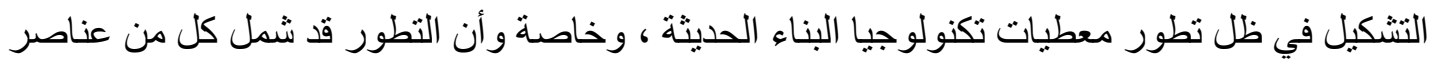

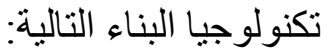

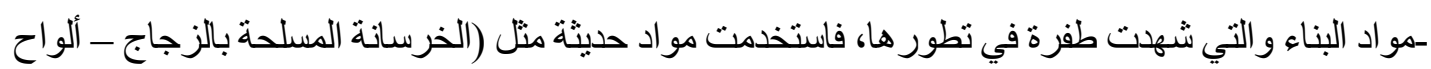

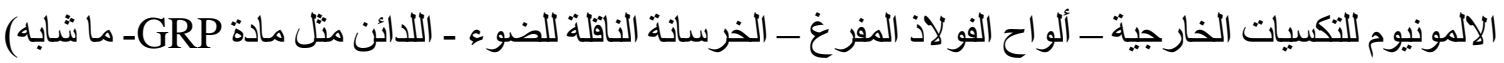

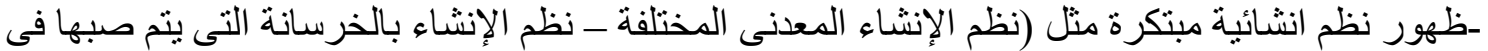

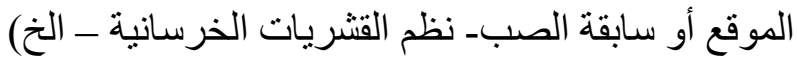

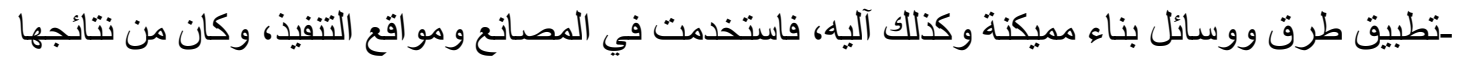

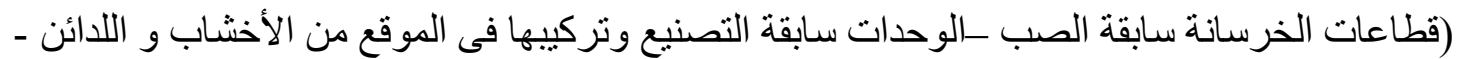

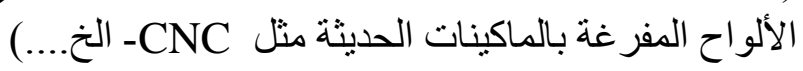

1-7-معايير اختيار عينات الاراسة التحليلة

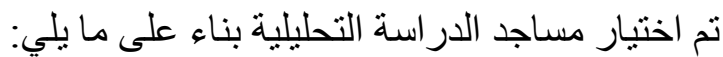

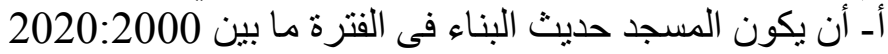

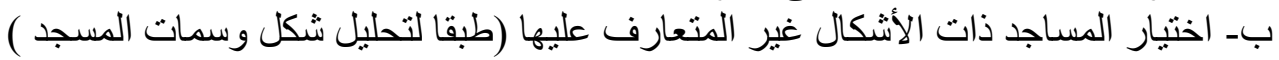
ج- اختيار العينات من مختلف الدول و المناطق (محليأ- عربيا- إقليميا- عالميأ اسلاميا - و وغير اسلاميا)

2-7-ملامح التغيير في عناصر التثكيل في العصر الدايث

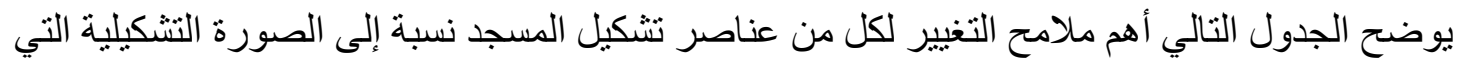

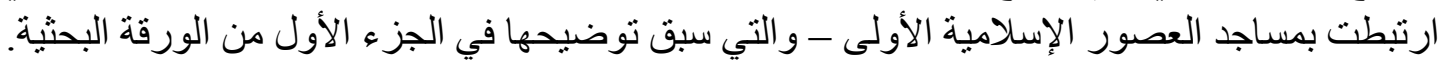

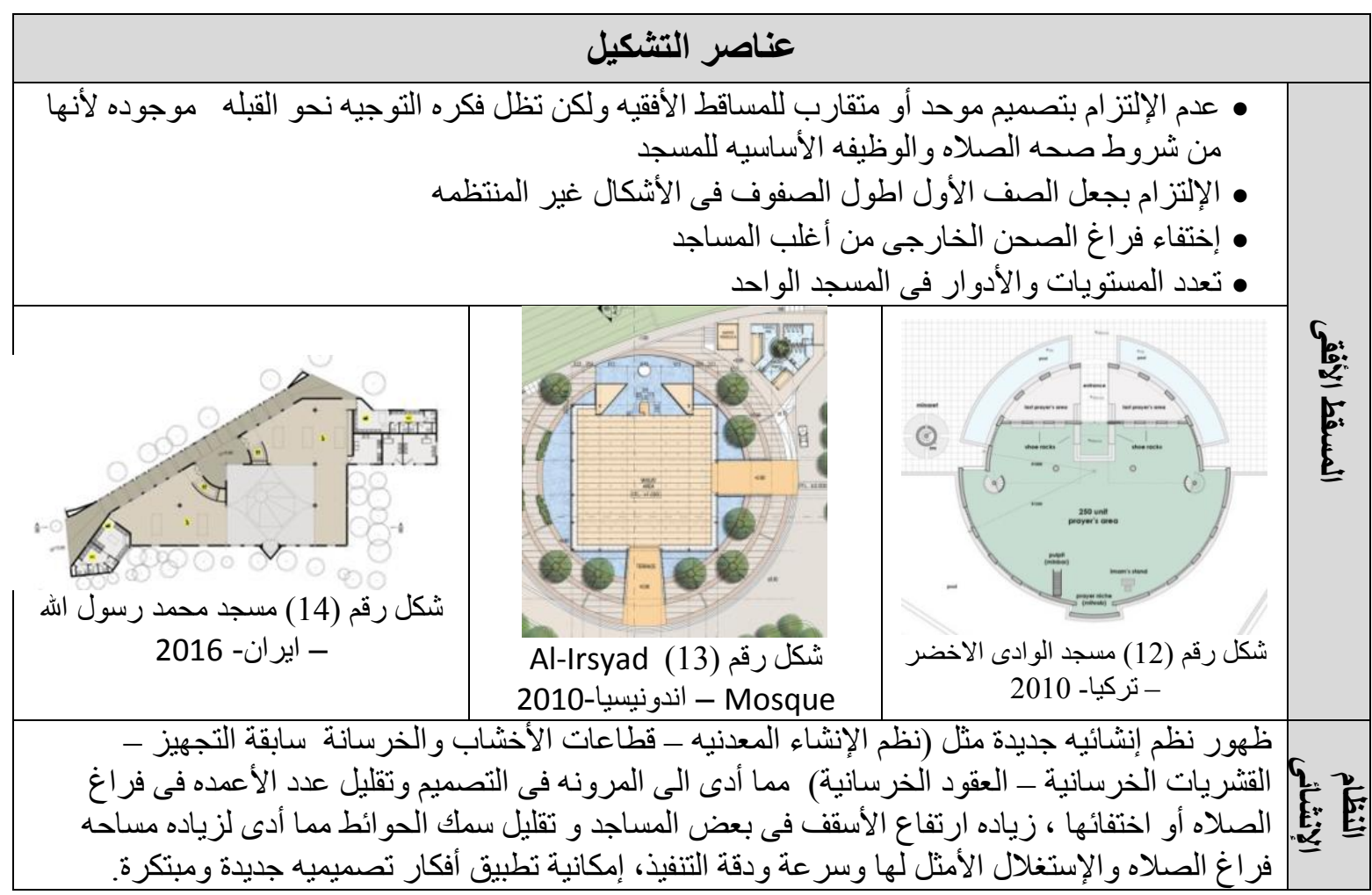




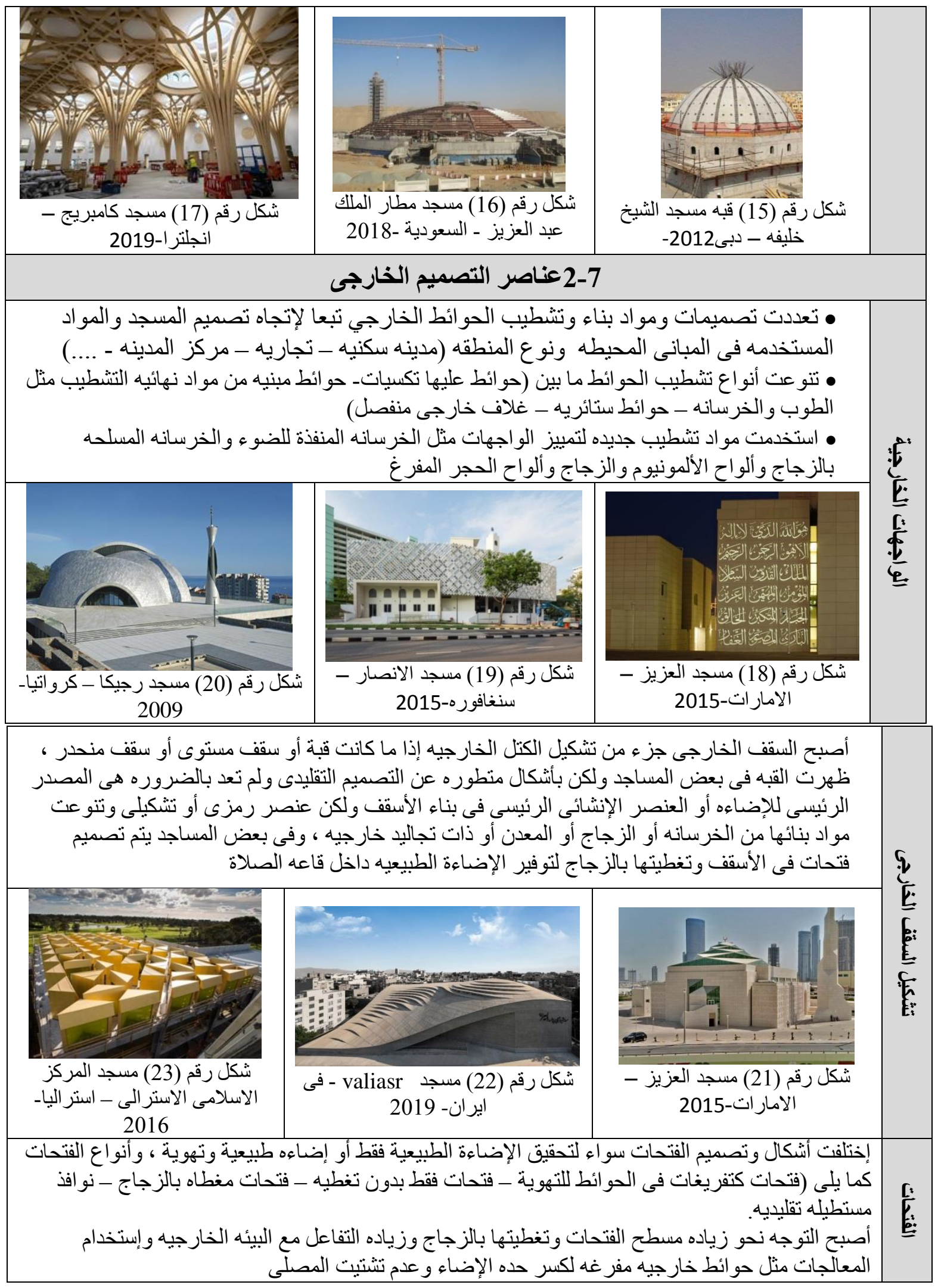




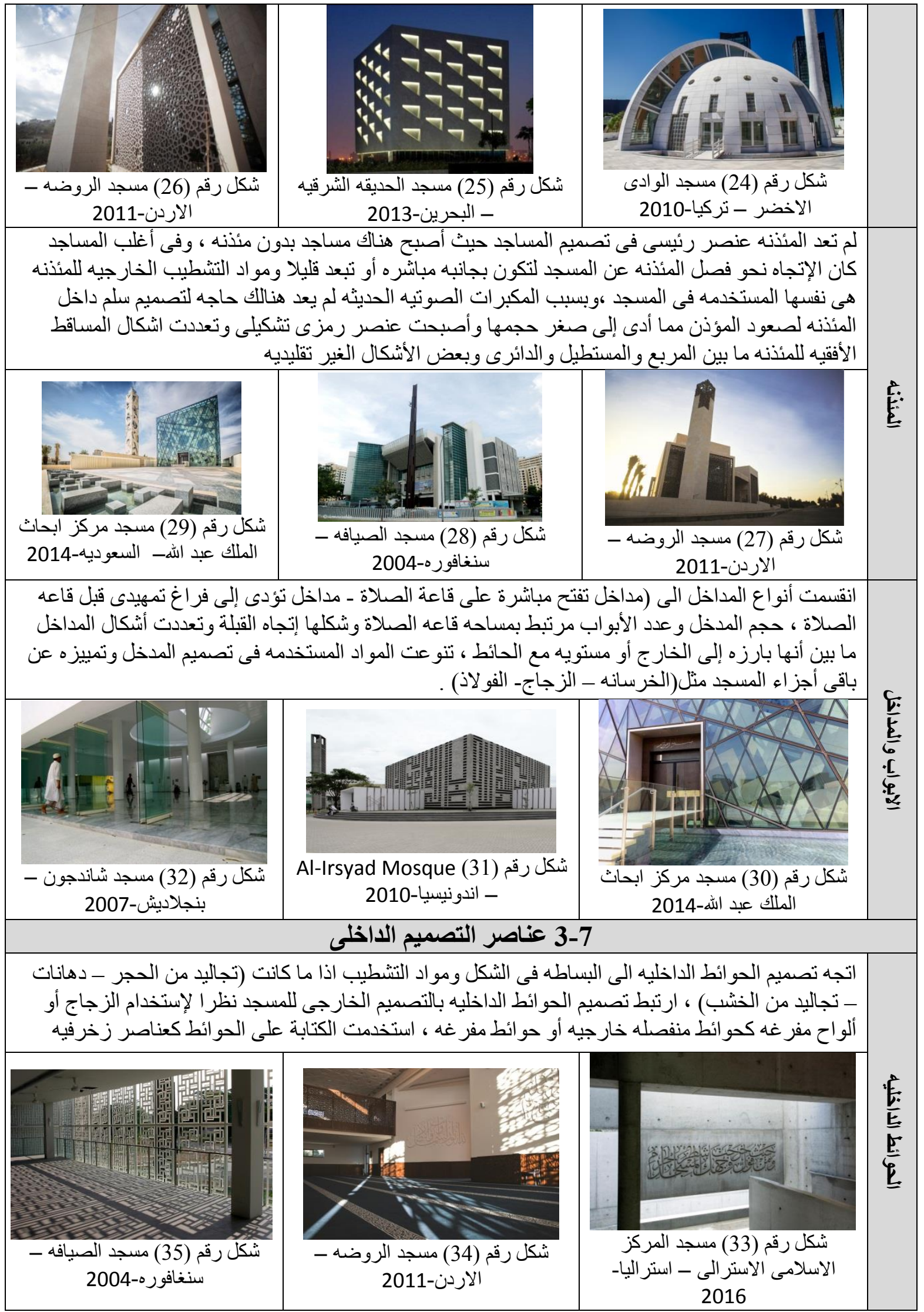




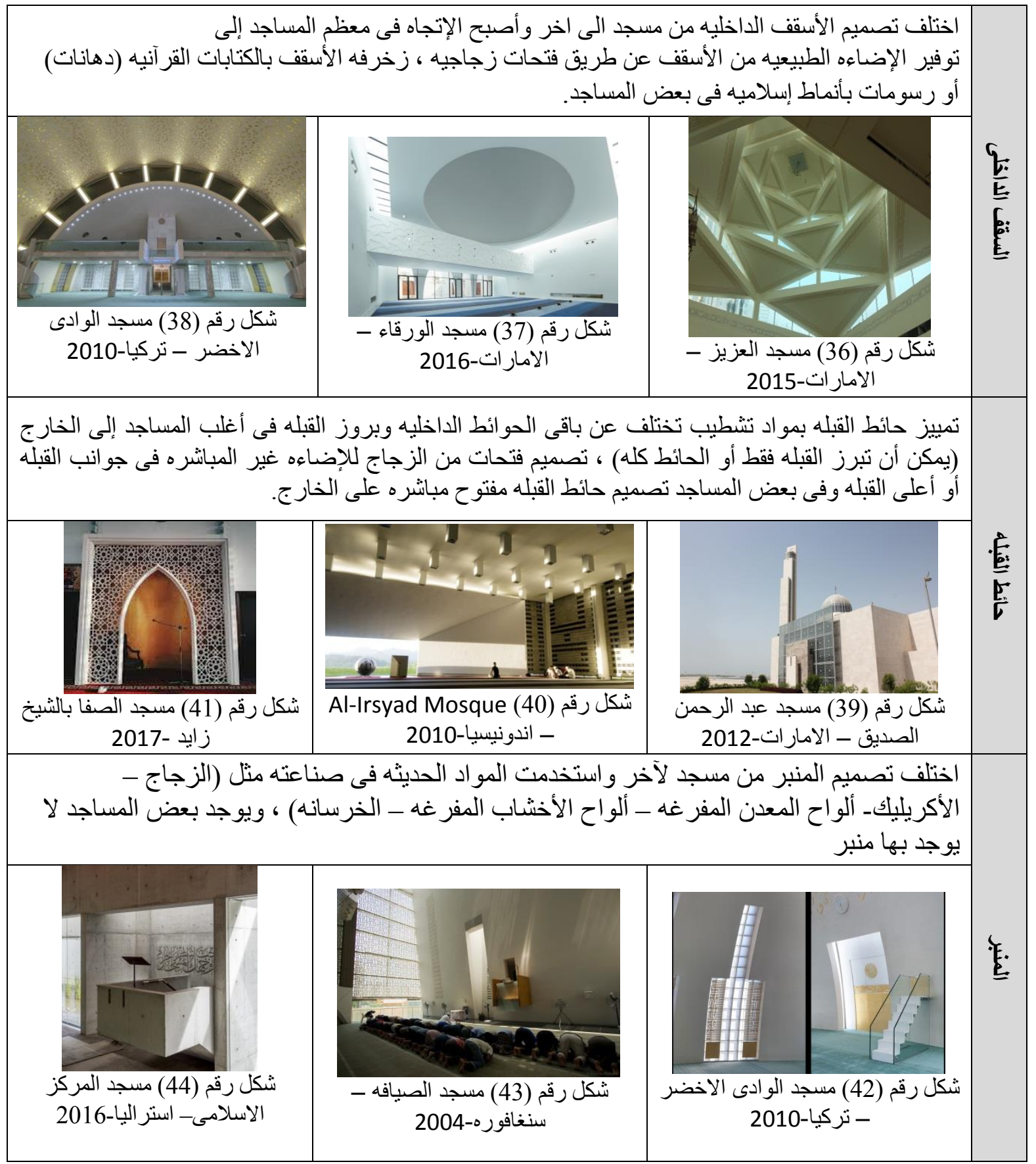

8- السمات العامه لتأثير معطيات تكنولوجيا البناء على المسجد (في العصور الاسلامية الحديثة)

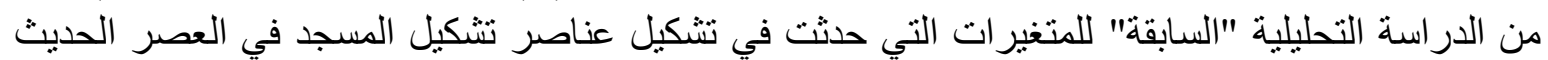

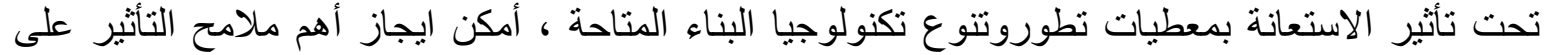

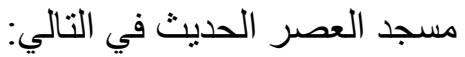

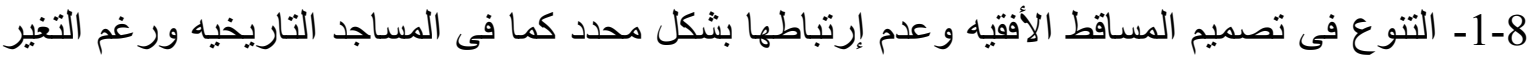
فى شكل المسقط الأفقى من مسجد لأخر إلا أن تصميم قاعه الصلاه منتظم لمر اعاة أن تكون صفوف الصلاهلاه 


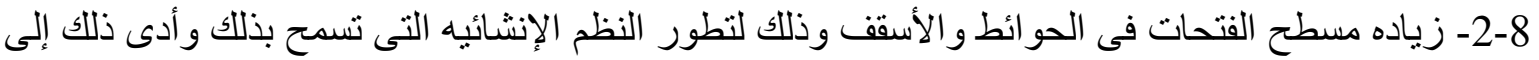

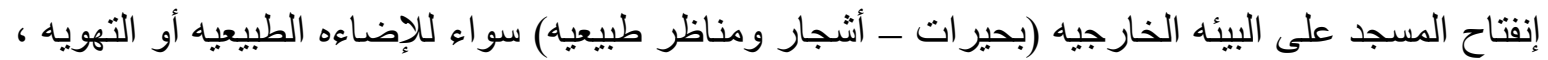
فأصبح المسجد مفتوح للخارج وليس للاخل (على الصحن) كما كان فى المساجد التاريخيه.

3-8-8 حائط القبلة أصبح له حلول تصميمية مختلفة بأن يكون مفتوح على البيئة الخارجية فى الإتجاه الأفقى (فتحات كنو افذ فى الحائط ) أو فى الإتجاه الر أسى (الفتحات فى السقف) وذلك سلك ساعد على توفير الإضـاءة و التهوية الطبيعية.

4-4- تعددت أشكال المداخل و عددها طبقا لمساحة المسجد و الإتجاه التصميمى له ، فى المساجد كبيرة المساحة

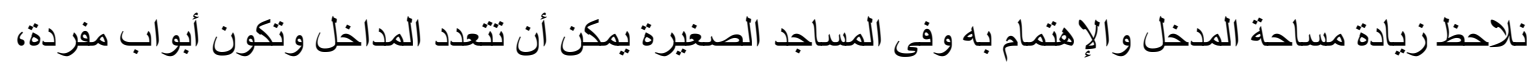
وتصميم معظم المداخل أنها فى نفس مستوى الواجهة (ليست بارزة أو أو غاطسة للاخدل).

5-8-8 لم يعد المنبر عنصر رئيسى من مكونات المسجد و إذا وجد فإنه يتميز بالبساطه وتعددت أثناله (معلق فى الحائط - مجرد منصه على مستوى الأرض لوقوف دون الإمام)، تنو عت مو اد إنشائه وتشطيبه.

6-6- تميزت الأسقف الداخلية بالبساطة والبعد عن الزخرفة بالأشكال والرسومات-إلا فى بعض المساجد-

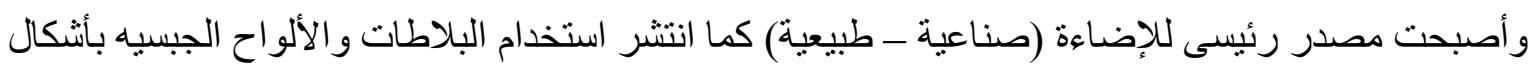
مختلفة أو المسطحات الزجاجية التى تغطى الفتحات في الأسقف.

\section{9- الجوانب السلبيه لتأثير التكنولوجيا على تصميم وتثكيل المسجد}

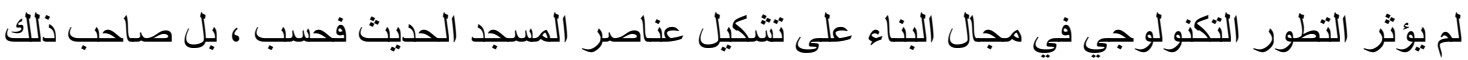

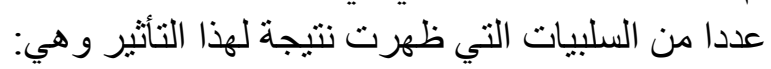

1-9- إرتفاعات بعض المساجد وتتكيلات الأسقف غير مناسبة للمقياس الإنسانى حيث كان الإهتمام بالثكل

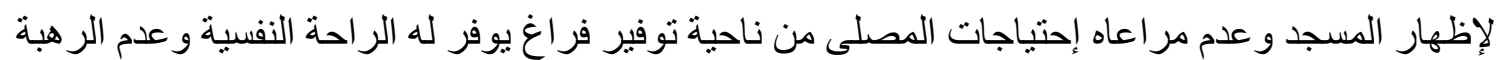

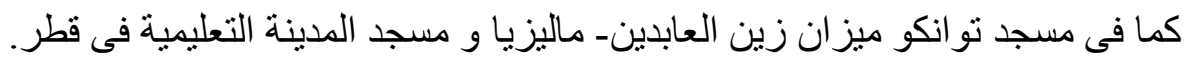

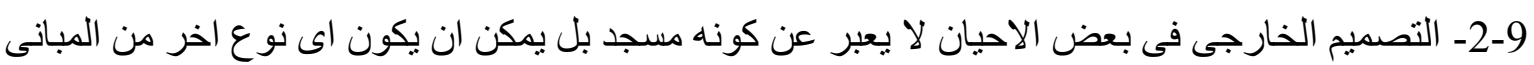

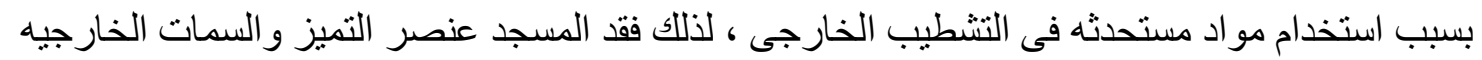
الو اضحه التى توضع كمحددات لتصنيف المساجد كما فى مسجد الإرصياد ــ اندونيسياو مسجد الصيافة ـ سنغافورة .

3-9- انفتاح المسجد على البيئه الخارجيه بدون عناصر فصل (نو افذ - حوائط) وزياده مسطحات الحوائط

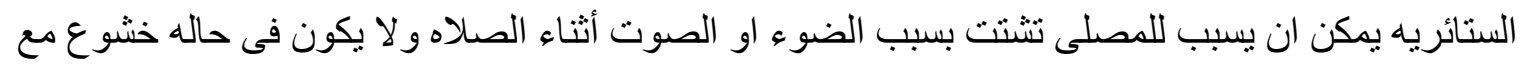
الله كما فى مسجد كولن - ألمانيا.

4-9- العناصر التصميمية و التشكيلية للمسجد لم تعد موحدة لكل مسجد من ناحية وجودها من عدمه أو شكلها

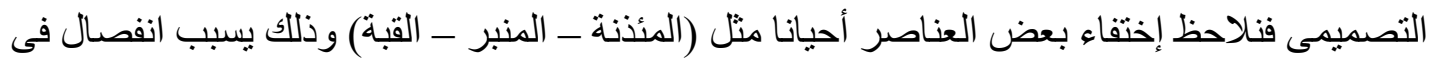

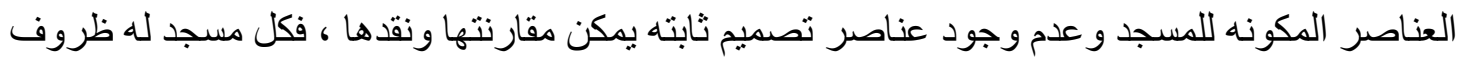
و عو امل تؤثر على بناءه وبالتالى تتأثر الفكره التصميميه بذلك. للك. 


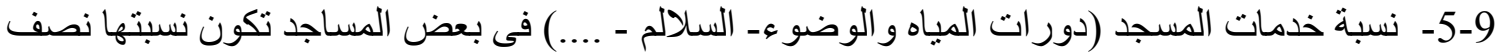

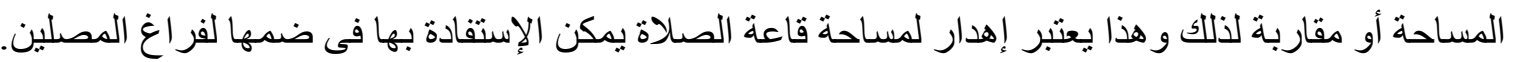
9-6- وجود المنبر و المحر اب ممتد بشكل أفقى طولى داخل قاعة الصلاة يسبب إهدار لفراغ الصلاة كان يمكن

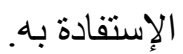

\section{0- الجواتب الإيجابية لتأثير التكنولوجيا على تصميم المسجد}

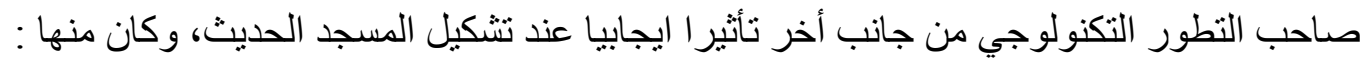
1-10- المساقط الأفقية للمسجد برغم إختلاف التشكيل الخارجى لكل مسجد إلا أنها تحقق معايير التصميم المناسبة من حيث الثكل (مستطيل - مربع - نصف دائرى-.....) وتصميم الصفوف الأولى لإستيعاب أكبر عدد من المصلين. 2-10- إستخدام النظم الإنشائية الحديثة فى المساجد مما كان له عدة جو انب إيجابية كما يلى:

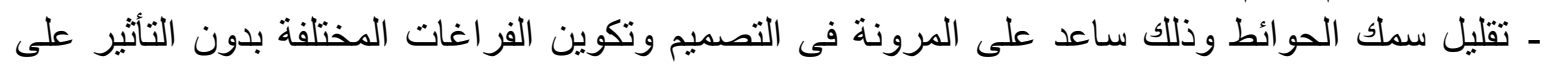
مساحة فر اغ الصلاة بتقليل مساحته.

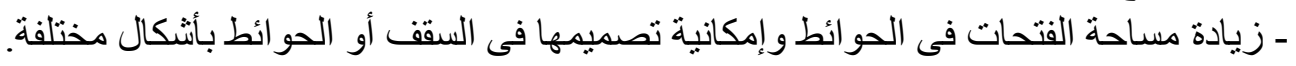

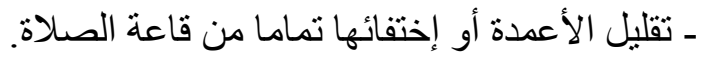
ـ ـتشكيلات الواجهات والأسقف الخارجية المميزة التى تتماثىى مع طابع كل منطقة و ورجة درجة الحرارة و الإحتياجات التصميمية.

ف-10-10- إستخدام مو اد البناء الحديثة ساعد على تحقيق حلول مناخية مثل(تصميم حوائط مفرغة لإلقاء الظلال

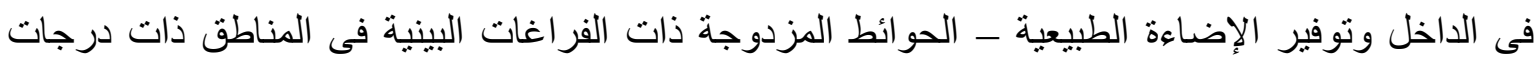
الحرارة العالية - حوائط ذات فراغات لتوفير التهوية الطبيعية) وحلول لتوفير الوقت ودقة التوات التنفيذ مثل إستخدام

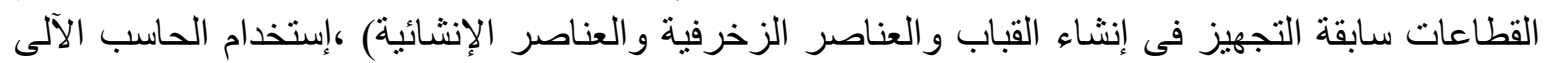
لتصميم القطاعات سابقة التجهيز والرسومات النمطية و التى أصبحت بديل لطرق الزئه وخارف التقليدية. 4-10- محاكاة العناصر التقليدية للمسجد (القبة - المئذنة ـ الزخارف - المنبر - ...) وتصميمها بشكل جديد ومواد إنشائية حديثة لتو اكب التطور التكنولوجى.

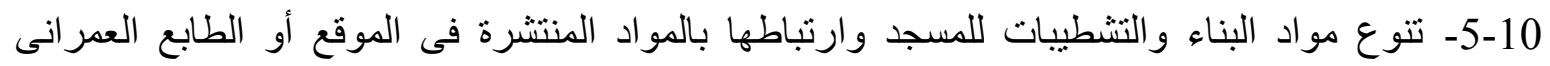

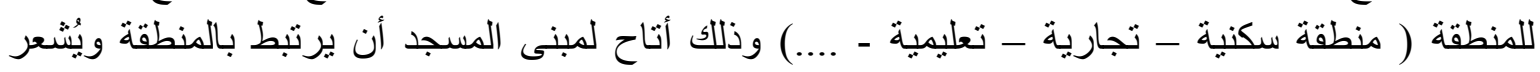

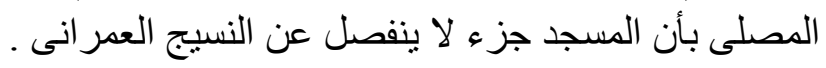

\section{1- منهجية تطبيق تكنولوجيا البناء عند تصميم وتثكيل المساجد فى العصر الحديث}

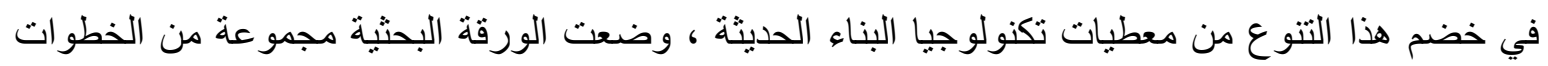
الأساسية التي يجب على مصمح المسجد الحديث ان يتبعها ، أولا: بهدف الحفاظ على الحى الوظيفة الأساسية

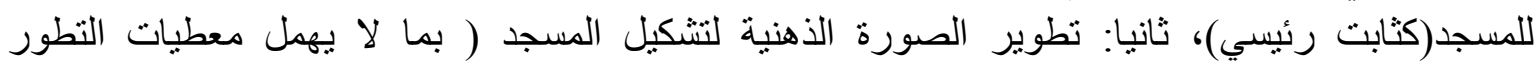

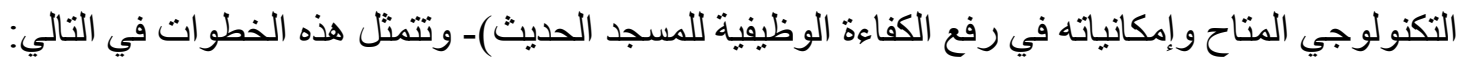


- 11-11 مرحلة التصميم على المصمم المعمارى بعد تحديد الإتجاه التصميمى للمسجد، أن يضع مقترحات استخدام مواد البناء

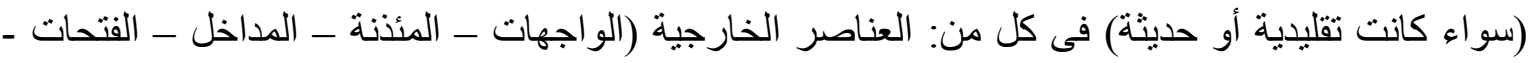

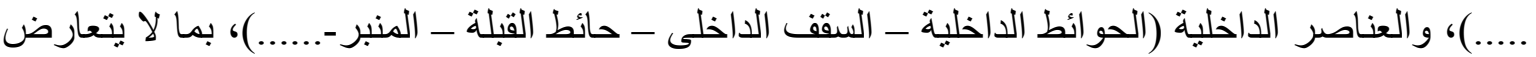
مع البعد الوظيفى لكل عنصر تصميمى. وبذلك يمكن تحقيق أقصي استفادة من المواد المتاحة، ومن ثم رفع

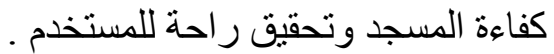

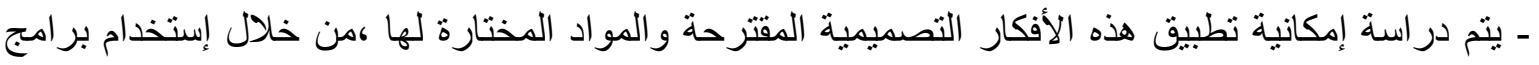

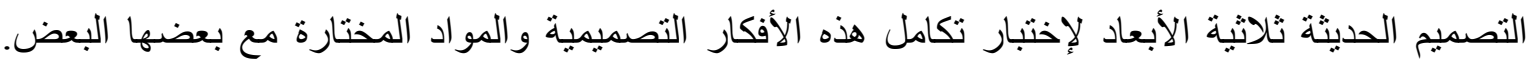

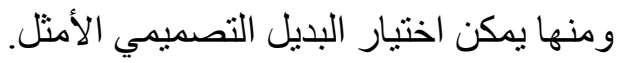

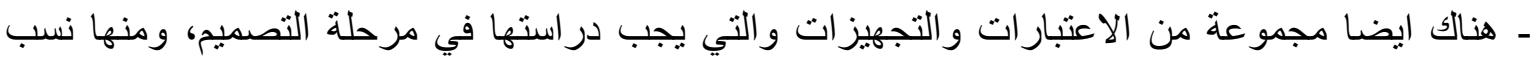

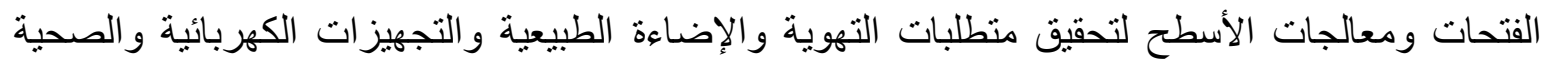
و الميكانيكية ...الخ لضمان الكفاءة البيئية و الوظيفية في آن آن واحد.

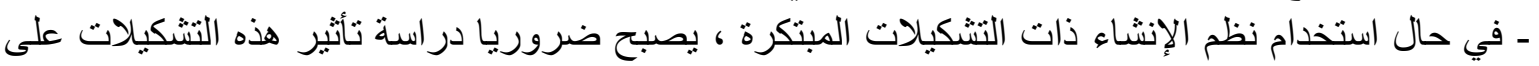

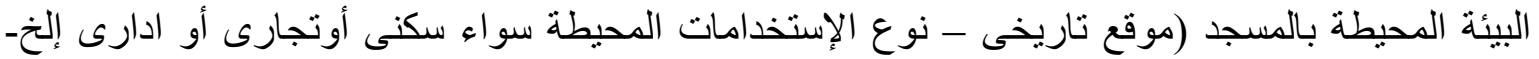

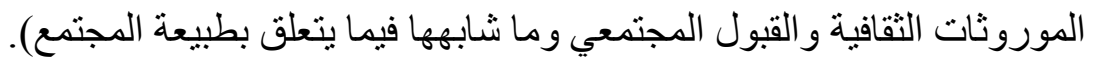

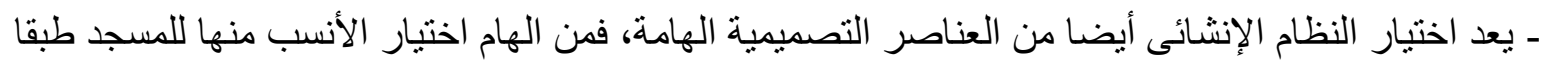

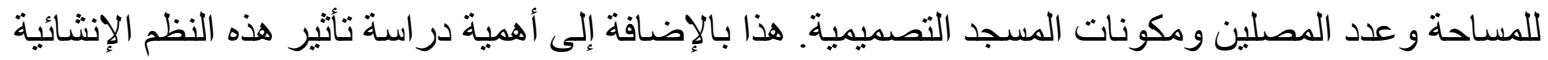

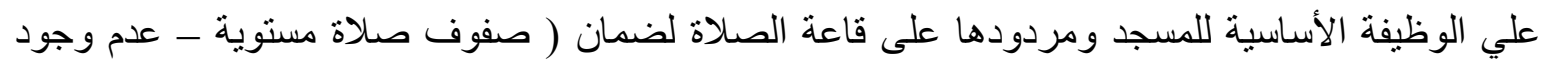

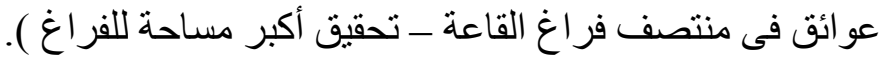

\section{2-11 مرحلة التنفيذ}

ـ قبل البدء في مرحلة التنفيذ، يجب التأكد من أن طرق التنفيذ المختارة وخاصة الحديثة منها تتوفر لها مقومات

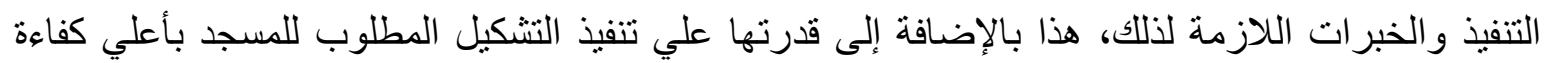
ودقة مع توفير الوقت و الجهد و التكلفة في آن واحد.

\section{3-11 مرحلة ما بعد التنفيذ}

ـ لايقتصر دور المصمم على الإنتهاء من تصميم وتتفيذ المسجد فحسب، بل و عليه أيضا رصد وتحليل مدى

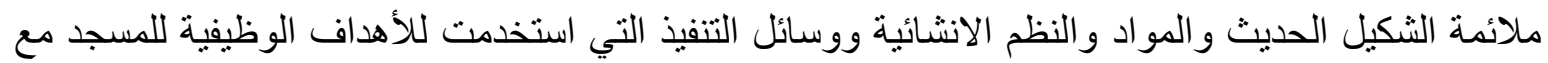

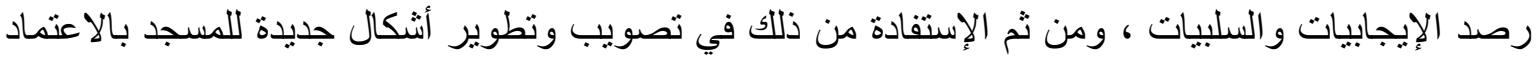

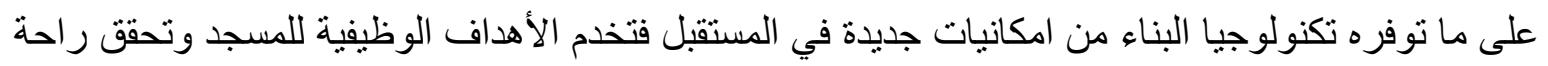

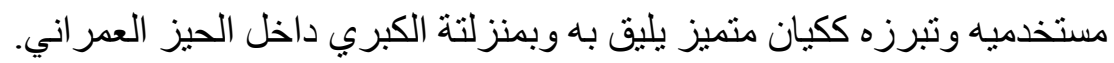


(1) محمود محمد ادريس ،على بن سالم ـ ندوه عماره المساجد ـ تعديلات المساجد (المعالجات و الحلول النابعه من

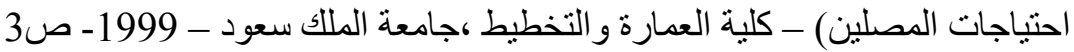

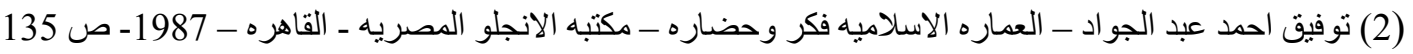

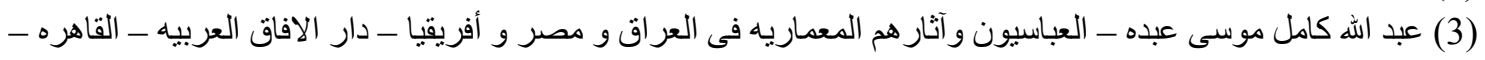

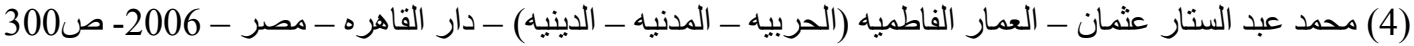

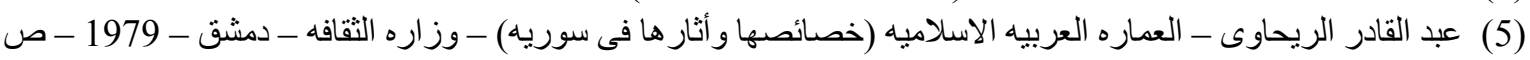

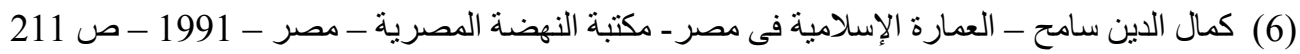
(7) عبد القادر الريحاوى - العماره العربيه الاسلاميه (خصائصها وأثنار ها فى سوريه) - وزاره الثارية الثقافه ـ دمشق - 1979 - ص

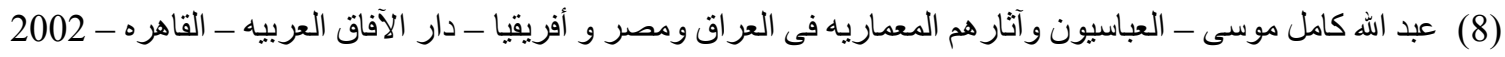

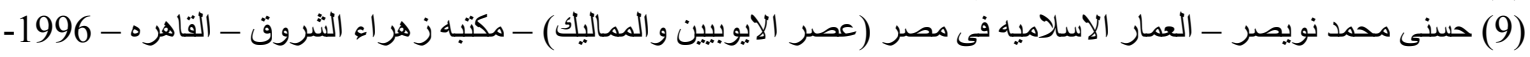

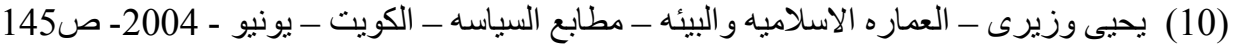

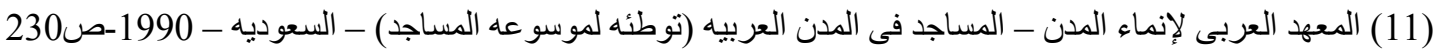

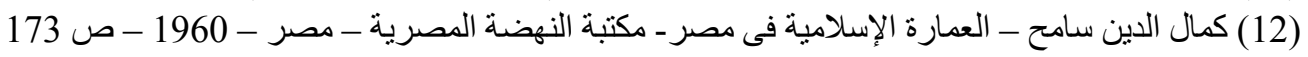
(13) المعهد العربى لإنماء المدن - المساجد فى الدن العربيه (توطئه لموسو عه المساجد) - السعوديه - 1990 ـ ص ص 254 :

(14) السيد عبد العزيز سالم - المآذن المصريه (نظره عامله على أصلها وتطور ها منذ الفتح العربى حتى الفتح العثمانى) -

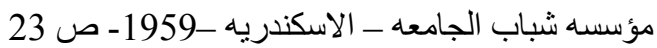

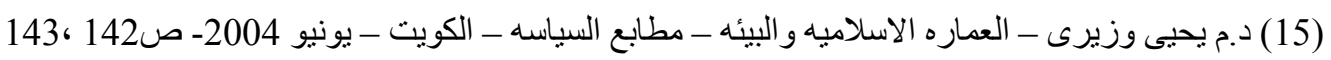

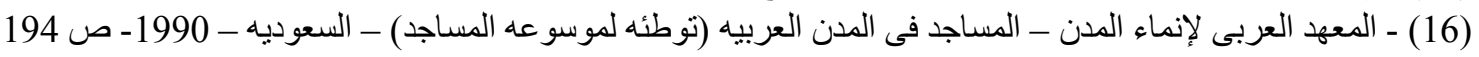
(17) محمد ماجد عباس خلوصىى- المسجد عماره وطر از وتاريخ(الجزء الثانى)- دار قابس للطباعه و النشر و التوزيع- 1998-

(18) توفيق احمد عبد الجواد - تاريخ العماره والفنون (فى العصور المتوسطه والاوروبيه و الاسلاميه) - مكتبه الانجلو

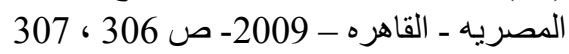

(19) يحيى وزيرى- موسو عه عناصر العماره الاسلاميه - مكتبه مدبولى ـ القاهرهـ

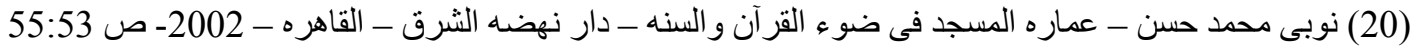
(21) ياسمين طلعت اسماعيل- عماره المر اكز الاسلاميه (دراسه مقارنه لأسس ومحددات التصميج) - جامعه حلو انـ- هندسه

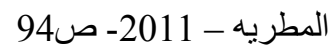
(22) محمد حسن نوفل - المعايير التصميميه لعماره المساجد - أبحاث ندوه عماره المساجد ـ كليه العماره و التخطبط (جامعه

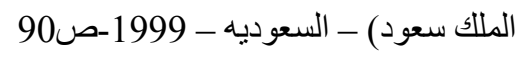
(23) محمد ماجد عباس خلوصىى- المسجد عماره وطر از وتاريخ(الجزء الاول)ـ- دار قابس للطباعه و النشر و التوزيع- 1998ص ص 5 (24) (24) ( 6شارى عبد الله النعيم - وليد أحمد السيد ) ،(جائزه عبد اللطيف الفوز ان لعماره المساجد ـ منار ات الخليج العربى) ، مكتبه الملك فهز الوطنيه ، السعوديه ، 2016.

(25)Azim A. Aziz - Modern Mosques Design - Independently published - 2017

(26) Wael A. Yousef Mousa - Modern Mosques in Malaysia: Between Regionalism and Eclecticism - Penerbit Universiti Sains Malaysia - 2019

(27) Abdullatif Al Fozan Award - Nominated mosques (third cycle 2017-2020)- Uia pdf presentation

(28) Rudolf Stegers - Sacred Buildings - Die Deutsche Nationalbibliothek- Germany - 2008 